\title{
The Role of AMPA Receptor Gating in the Development of High-Fidelity Neurotransmission at the Calyx of Held Synapse
}

\author{
Indu Joshi, Shahira Shokralla, Paul Titis, and Lu-Yang Wang \\ The Program for Brain and Behavioral Research and Division of Neurology, The Hospital for Sick Children and Department of Physiology, University of \\ Toronto, Toronto, Ontario, Canada M5G, 1X8
}

\begin{abstract}
During early postnatal development of auditory synapses, the decay time course of AMPA receptor (AMPAR) EPSCs accelerates markedly, but the mechanisms underlying this process remain uncertain. Using the developing calyx of Held synapse in the mouse auditory brainstem, we have examined presynaptic and postsynaptic elements that may regulate decay kinetics of AMPAR EPSCs. We found that the decay time kinetics was voltage dependent in both immature and mature synapses, being slower at positive potentials than negative potentials. By recording evoked miniature events in extracellular $\mathrm{Ca}^{2+}$ or $\mathrm{Sr}^{2+}$, we revealed a significant decrease in decay time constants of EPSCs as maturation progresses. On the basis of internal and external polyamine block of AMPAR EPSCs and immunohistochemistry assays with subunit-specific antibodies, we demonstrated that the glutamate receptor (GluR) 2 subunit is virtually absent at all developmental ages. Antibody staining patterns suggest a gradual shift in subunit composition from GluR1- to GluR3/4-dominant phenotypes. Kinetic analyses of deactivation, desensitization, and recovery from desensitization in outside-out patches in response to ultrafast application of glutamate lend supportive evidence that such a shift in the gating phenotype likely accounts for the accelerated time course throughout development. Finally, by pharmacologically manipulating AMPAR gating and using simulated EPSCs to evoke action potentials, we demonstrated that rapid decay kinetics of AMPAR EPSCs is essential for this synapse to accommodate high-frequency firing without compromising spike amplitude. Hence, developmental alterations in the subunit composition likely dictate changes in the time course of AMPAR EPSCs and play an indispensable role in the refinement of high-fidelity neurotransmission at the calyx of Held synapse.
\end{abstract}

Key words: calyx of Held-MNTB synapse; $\mathrm{Ca}^{2+}$-permeable AMPA receptors; polyamine; synaptic transmission; spike firing; developmental plasticity

\section{Introduction}

Fast excitatory synaptic transmission in a vast majority of central synapses is mediated by the neurotransmitter glutamate and its primary ionotropic receptors including NMDA and AMPA receptors (NMDARs and AMPARs). These receptors are heteromultimeric structures: NMDARs are composed of the NR1 and NR2 subfamilies (NR2A-D), whereas AMPARs are formed of varying combinations of subunits glutamate receptors (GluRs) 1-4. NMDARs are thought to be essential for various forms of synaptic plasticity, whereas AMPARs govern the efficacy and fidelity of synaptic transmission. Numerous studies have demonstrated that the size and time course of EPSCs may undergo sig-

Received April 10, 2003; revised 0ct. 29, 2003; accepted 0ct. 29, 2003.

This work was supported by grants from the Canadian Institutes of Health Research (CIHR) (L.-Y.W.) and "The Synapse" group at the University of Toronto. I.J. is the recipient of an Ontario Graduate Scholarship and The Hospital for Sick Children Research and Training Center Studentship. L.-Y.W. is the recipient of a CIHR New Investigatorship and the Canada Research Chair in Brain and Behaviour. We thank Michael Fedchyshyn and Shilpy Grupta for coding the EPSC simulation program, and Danuta Zylka, Amy Yang, and Tina Epps for assistance and discussion.

Correspondence should be addressed to Dr. L.-Y. Wang, Division of Neurology, The Hospital for Sick Children, 555 University Avenue, Toronto, Ontario, Canada M5G, 1X8. E-mail: luyang.wang@utoronto.ca.

DOI:10.1523/JNEUROSCI.1074-03.2004

Copyright $\odot 2004$ Society for Neuroscience $\quad$ 0270-6474/04/240183-14\$15.00/0 nificant changes in response to acute synaptic stimulation or chronic sensory activity during development (ConstantinePaton and Cline, 1998). In developing synapses, subunit switching is thought to be a major mechanism that underlies changes in the decay kinetics of EPSCs. For example, NMDAR EPSCs shorten progressively in various brain regions (Carmignoto and Vicini, 1992; Hestrin, 1992; Takahashi et al., 1996), and a reduction in the NR2B subunit in the channel complex likely accounts for accelerated decay. Such changes in NMDAR EPSC kinetics reduce the amount of $\mathrm{Ca}^{2+}$ influx through NMDARs and may have a strong impact on the direction and extent of synaptic plasticity. On the contrary, although kinetic changes in AMPAR EPSCs have also been described (Bellingham et al., 1998; Lawrence and Trussell, 2000; Taschenberger and von Gersdorff, 2000; Futai et al., 2001; Kumar et al., 2002; Wall et al., 2002), few studies have established molecular correlates for such changes and physiological consequences (Jonas et al., 1994; Geiger et al., 1995).

In the developing auditory system, we and other groups have described an age-dependent acceleration in the decay kinetics of evoked AMPAR EPSCs (Bellingham et al., 1998; Taschenberger and von Gersdorff, 2000; Futai et al., 2001; Iwasaki and Takahashi, 2001; Joshi and Wang, 2002). However, there have been conflicting 
reports regarding the underlying mechanisms that contribute to these developmental changes. For example, Chuhma and Ohmori (1998) suggest that asynchrony of events contributes to slower decay kinetics in younger synapses at the calyx of Held synapse in the medial nucleus of the trapezoid body (MNTB), in contrast to the findings of others (Taschenberger and von Gersdorff, 2000; Iwasaki and Takahashi, 2001). Whether there is a subunit switch in synaptic AMPAR composition from slower gating subunits to faster ones during early postnatal stages of the calyx of Held synapse has yet to be determined.

Auditory synapses are particularly enriched in the fast gating GluR4 flop subunit, and AMPARs at these synapses are often permeable to $\mathrm{Ca}^{2+}$ because of a lack of the GluR2 subunit, which eliminates $\mathrm{Ca}^{2+}$ permeability (Geiger et al., 1995; Otis et al., 1995; Zhou et al., 1995; Wang et al., 1998; Caicedo and Eybalin, 1999; Ravindranathan et al., 2000). It is unknown, however, whether $\mathrm{Ca}^{2+}$ permeability is conferred to synaptic AMPARs at the onset of synaptogenesis or a later developmental stage. Given that $\mathrm{Ca}^{2+}$ influx is a critical second messenger to initiate a cascade of molecular events leading to various forms of synaptic plasticity, understanding the onset time frame of $\mathrm{Ca}^{2+}$ permeability of synaptic AMPARs is of particular importance for understanding developmental plasticity at these fast synapses.

Using the mouse calyx of Held-MNTB synapse, we addressed the aforementioned issues. Our results indicate that developmental speeding of AMPAR EPSCs is likely accounted for by a shift in the relative dominance from GluR1 to GluR3/4 subunits independent of GluR2. Such fast gating kinetics of AMPAR EPSCs acquired at mature stages of synaptic development is indispensable for the calyx of Held synapse to achieve high-frequency neurotransmission.

A portion of this study has been published previously in abstract form (Joshi et al., 2001).

\section{Materials and Methods}

Slice preparation. Mice were housed in the facility certified by the Canadian Council of Animal Care and used for this study according to a protocol approved by the Hospital for Sick Children Animal Care Committee. Brainstem slices were prepared from postnatal day (P) 3-18 mice (CD1/C57 black) as described previously (Forsythe and Barnes-Davies, 1993; Wang, 2000). Mice were decapitated with a small guillotine, and brains were rapidly dissected and immersed in ice-cold artificial CSF (aCSF) containing (in $\mathrm{mm}$ ): $125 \mathrm{NaCl}, 2.5 \mathrm{KCl}, 10$ glucose, 1.25 $\mathrm{NaH}_{2} \mathrm{PO}_{4}, 2 \mathrm{Na}$-pyruvate, 3 myo-inositol, 0.5 ascorbic acid, $26 \mathrm{NaHCO}_{3}$, $1 \mathrm{MgCl}_{2}$, and $2 \mathrm{CaCl}_{2}$ at a $\mathrm{pH}$ of 7.3 when bubbled in $95 \% \mathrm{O}_{2}$ and $5 \%$ $\mathrm{CO}_{2}$. Transverse slices of the auditory brainstem were cut at a thickness of $250-300 \mu \mathrm{m}$ using a Vibratome (Leica VT100S), incubated at $37^{\circ} \mathrm{C}$ for 1 $\mathrm{hr}$, and kept at room temperature $\left(20-22^{\circ} \mathrm{C}\right)$ thereafter for experiments.

Electrophysiology. Whole-cell patch-clamp recordings were made from visually identifiable postsynaptic MNTB neurons with an Axopatch 200B amplifier (Axon Instruments, Foster City, CA). For voltage-clamp recordings of EPSCs, the patch electrodes had a resistance of 2-4 M $\Omega$ and were filled with intracellular solution containing (in $\mathrm{mm}$ ): 97.5 K-gluconate, $32.5 \mathrm{CsCl}, 5$ EGTA, 10 HEPES, $1 \mathrm{MgCl}_{2}$, 30 TEA, and 3 lidocaine $N$-ethyl bromide (QX314), pH 7.2. In specified experiments, spermine $(100 \mu \mathrm{M})$ was added to the intracellular solution. For currentclamp experiments, fast-clamp mode $\left(I_{\text {fast }}\right)$ of Axopatch $200 \mathrm{~B}$ was used and $\mathrm{KCl}$ replaced $\mathrm{CsCl}$ in the same intracellular solution, whereas TEA and QX314 were omitted. To block inhibitory inputs, bicuculline (10 $\mu \mathrm{M})$ and strychnine $(1 \mu \mathrm{M})$ were added to the aCSF. EPSCs and spikes (except for those elicited by injections of simulated EPSCs to MNTB neurons in Fig. $6 F, G$ ) were evoked by stimulating the presynaptic axon fiber bundles with a bipolar platinum electrode placed near the midline of the slice. Stimulation voltage was set at $20-30 \%$ above the threshold. Series resistance for voltage-clamp recordings was 4-8 M $\Omega$ and com- pensated to $90 \%$ with a lag of $10 \mu \mathrm{sec}$. For outside-out patch recordings, electrodes (1.5-2.5 M $\Omega$ ) were filled with intracellular solution containing in (mM): $140 \mathrm{CsF}, 10$ BAPTA, $1 \mathrm{CaCl}_{2}, 2 \mathrm{MgCl}_{2}, 10 \mathrm{HEPES}$, and 4 $\mathrm{K}_{2} \mathrm{ATP}, \mathrm{pH}$ 7.3. Shortly after whole-cell configuration was established, the pipette was slowly pulled away from the recorded MNTB neuron to form an excised outside-out patch for experiments with a fast-perfusion system placed near the slice. This perfusion system consisted of a twobarrel theta-glass pipette (tip size $\sim 300 \mu \mathrm{m}$ ) mounted on a piezoelectric bimorph (Morgan Matroc). Patches were positioned near the interface of adjacent barrels of the theta pipette that could be rapidly moved by applying a constant voltage step across the bimorph (100 V; Grass Instruments). The solution exchange time was $\sim 100-200 \mu$ sec estimated with open-tip patch electrode response to a rapid barrel switch from normal to diluted aCSF $(20 \sim 30 \%)$. To measure the kinetic properties of AMPARs, excised patches were perfused continuously with control ACSF solution flowing from one barrel and rapidly switched to the other barrel with the same solution containing glutamate $(10 \mathrm{~mm})$ for a designated time (see Fig. 5 legend). Data were filtered at $2 \mathrm{kHz}$, digitized at $10-20 \mathrm{kHz}$, acquired on-line, and analyzed off-line with pClamp7 software (Axon Instruments). For some experiments, current density (nanoamperes per picofarad) was estimated by normalizing the peak amplitudes of EPSCs to the capacitance of the recorded cell. Averaged data are expressed as mean \pm SE. For pharmacological experiments, drugs were mixed into aCSF and applied focally to the recorded cells using a square glass pipette ( $400 \mu \mathrm{m}$ in width) placed on the surface of the slice near the vicinity of the cells to be recorded. The jet solution had a linear range of 1-2 $\mathrm{mm}$ and completely replaced the solution surrounding the recording region within $30-60 \mathrm{sec}$. Bicuculline, strychnine, kainate, glutamate, and cyclothiazide were obtained from Sigma (St. Louis, MO), and $(5 R, 10 S)$ (+)-5-methyl-10,11-dihydro-5H-dibenzo[a,d]cyclohepten-5,10-imine hydrogen maleate (MK-801), QX314, and $N$-(4-hydroxyphenylpropanoyl)-spermine (HPP-SP) were from Tocris.

Immunohistochemistry. Mice of ages P5/6, P9/10, and P18-20 were anesthetized with halothane and perfused through the left cardiac ventricle with cold normal saline followed by $4 \%$ paraformaldehyde (PFA) in PBS, pH 7.4. Brains were postfixed overnight in 4\% PFA, cryoprotected in $30 \%$ sucrose in PBS, and frozen in isopentane. Coronal sections $(20 \mu \mathrm{m})$ were obtained using a cryostat and mounted onto Superfrost slides. Sections were washed with PBS, pH 7.4, blocked with 10\% normal goat serum (Vector Laboratories, Burlingame, CA) in PBS for $1 \mathrm{hr}$, and incubated with primary antibody in blocking serum for $72 \mathrm{hr}$. The GluR1, GluR2/3, and GluR4 antibodies (Chemicon, Temecula, CA) were used at a concentration of $3 \mu \mathrm{g} / \mathrm{ml}$. GluR2 was diluted to $1 \mu \mathrm{g} / \mathrm{ml}$, and the primary antibody incubation was omitted for control slides. Sections were rinsed with PBS, treated with $0.3 \%$ hydrogen peroxide for $20 \mathrm{~min}$, and washed with PBS. Biotinylated anti-rabbit IgG (1:200; Vector Laboratories) in blocking serum was added and then rinsed. The sections were treated with Vectastain ABC Reagent (Vector Laboratories) and Sigma Fast DAB Peroxidase Substrate Set (Sigma) according to the manufacturer's instructions. After the color reaction, slices were dehydrated in a graded series of ethanol, cleared with Histoclear, and visualized under a light microscope. Digital pictures were obtained using a Sony 3CCD camera and converted to an eight-bit grayscale image. The average pixel intensities of individual MNTB neurons were calculated using Axon Imaging Workbench Software (Axon Instruments). These were normalized to control MNTB neurons and plotted to display the percentage increase in pixel intensity.

\section{Results \\ Developmental dependence and voltage dependence of AMPAR EPSC decay kinetics}

To examine the kinetic properties of AMPAR EPSCs during early postnatal development, we made whole-cell voltage-clamp recordings from postsynaptic MNTB cells from both young (P7) 
and mature synapses (P14). We used the specific and irreversible NMDAR open channel blocker MK-801 $(10 \mu \mathrm{M})$ to eliminate any NMDAR residual currents and isolate AMPAR EPSCs. Figure 1 shows two recordings from P7 and P14 synapses before and after MK-801 application. Traces superimposed before and after MK801 application for P7 and P14 synapses (Fig. $1 A, B$ ) show that the characteristic slower NMDA component of the EPSC was blocked, leaving only the fast component of AMPAR EPSCs (arrows). The AMPAR EPSCs from P14 synapses have much faster decay kinetics than that from P7 synapses. We further investigated the decay kinetics of AMPAR EPSCs across a wide spectrum of holding potentials ( +60 to $-60 \mathrm{mV}$ in $20 \mathrm{mV}$ increments) in the presence of MK-801. Figure 1, $C$ and $D$, shows two sets of data from a P7 and a P14 synapse, in which the decay phase for AMPAR EPSCs (dotted lines) recorded at each voltage step was fitted by a single exponential function (solid thick lines). There is a significant difference in the decay kinetics at any given test potential, as illustrated in the plot of time constants $(\tau)$ against holding potentials for the two age groups (Fig. 1E) [P7, $2.72 \pm$ $0.18 \mathrm{msec}(+60 \mathrm{mV}), 1.72 \pm 0.07 \mathrm{msec}(-60 \mathrm{mV})$ vs P14, $0.96 \pm$ $0.11 \mathrm{msec}(+60 \mathrm{mV}), 0.67 \pm 0.06 \mathrm{msec}(-60 \mathrm{mV})]$. Interestingly, we found that the $\tau$ values of AMPAR EPSCs are voltage dependent and well described by a linear function for both P7 and P14 synapses. When the $\tau$ value at any given potential was normalized to that at $+60 \mathrm{mV}$, we noted that slopes derived from linear fittings to the data from both age groups were similar (Fig. $1 F)$. As a potent use-dependent, irreversible, open channel blocker, it seems unlikely that MK-801 would dislodge from NMDARs at positive potentials. Because similar results were obtained when other competitive and noncompetitive NMDAR antagonists such as DL-2-amino-5-phosphonopentanoic acid (APV) and 7-chloro-kynurenic acid were used to block NMDAR EPSCs (data not shown), we suggest that the voltage dependence of decay kinetics is an intrinsic feature of evoked AMPAR EPSCs.

When kinetic properties of spontaneous miniature EPSCs (mEPSCs) are compared at $+60 \mathrm{mV}$ and $-60 \mathrm{mV}$ in P7 and P14 synapses, we found that as with the evoked responses, $\tau$ values at $+60 \mathrm{mV}$ were always greater than that at $-60 \mathrm{mV}$ for either age group [P7, $0.73 \pm 0.04 \mathrm{msec}(+60 \mathrm{mV}), 0.58 \pm 0.02 \mathrm{msec}(-60$ $\mathrm{mV})$ vs $\mathrm{P} 14,0.60 \pm 0.06 \mathrm{msec}(+60 \mathrm{mV}), 0.43 \pm 0.03 \mathrm{msec}(-60$ $\mathrm{mV})$ ] (Fig. 1G,H). Noticeably, spontaneous mEPSCs from P7 synapses displayed slower decay times than P14 synapses at corresponding potentials. Taken together, these observations indicate that the decay kinetics of both evoked AMPAR EPSCs and spontaneous mEPSCs display genuine developmental differences and voltage dependence.

It is generally accepted that evoked EPSCs originate from synchronized release of many vesicles in response to $\mathrm{Ca}^{2+}$ influx into the nerve terminal during an action potential, and individual spontaneous fusion events (e.g., mEPSCs) are basic quantal units for an action potential-evoked synaptic response. An early study by Denis and Miledi (1974), however, showed that spontaneous mEPSCs are not necessarily correlated with the quantal events that make up evoked EPSCs at regenerating frog neuromuscular junctions. Several recent studies (Hua et al., 1998; Washbourne et al., 2002) have even suggested that spontaneous and evoked release events may use distinct release machinery. We thus attempted to directly probe voltage and developmental dependence of kinetic properties of evoked unitary mEPSCs by using $\mathrm{Sr}^{2+}$, a divalent ion that is permeable through $\mathrm{Ca}^{2+}$ channels and increases the release probability at nerve terminals (Dodge et al., 1969; Goda and Stevens, 1994; Xu-Friedman and Regehr, 1999). Because of its slow kinetic properties, $\mathrm{Sr}^{2+}$ desynchronizes the release of individual vesicles and therefore causes an increase in delayed release (Xu-Friedman and Regehr, 1999). This unique property of $\mathrm{Sr}^{2+}$ allowed us to resolve and compare kinetic properties of evoked unitary quantal events from synapses at different age groups. Figure 1 I shows typical recordings from P7 and P14 synapses in $\mathrm{Sr}^{2+}$ (after MK-801 blockade of NMDARs), and in each case, delayed release events at +50 and $-60 \mathrm{mV}$ were collected and analyzed (Fig. $1 \mathrm{~J}$ ). Again, we confirmed a voltage dependence in the decay kinetics of evoked mEPSCs in $\mathrm{Sr}^{2+}$ similar to that of spontaneous mEPSCs in $\mathrm{Ca}^{2+}$ (Fig. 1I,J).

\section{Age-dependent changes in properties of the evoked unitary quantal events}

We used $\mathrm{Sr}^{2+}$ to further explore developmental changes in quantal properties of evoked mEPSCs across a broad age span (P617). In the same synapses, we recorded spontaneous and evoked (delayed) mEPSCs, first in control ACSF containing $\mathrm{Ca}^{2+}(2$ $\mathrm{mM}$ ) and then in the same ACSF solution in which $\mathrm{Ca}^{2+}$ was completely replaced by $\mathrm{Sr}^{2+}(2 \mathrm{mM})$. Figure $2 \mathrm{~A}$ depicts sample recordings of spontaneous mEPSCs in control solution at P8 and P15 synapses. Because of rare occurrences of spontaneous mEPSCs in young synapses, we simply compared the number of release events in a time block of $2 \mathrm{~min}$ (Fig. 2 B). Immature synapses evidently displayed fewer spontaneous or delayed release events in $\mathrm{Ca}^{2+}$ when compared with mature ones (Fig. $2 \mathrm{~A}, \mathrm{C}$ ). However, after desynchronization with extracellular $\mathrm{Sr}^{2+}$, we observed many evoked mEPSCs after an initial compound EPSC (peak graphically truncated) (Fig. 2D). As with the spontaneous mEPSCs, the number of events in P8 synapses was significantly fewer than in P14 synapses. Figure 2, $B$ and $E$, summarizes the number of events for young $(<\mathrm{P} 10)$ and old $(>\mathrm{P} 12)$ synapses for both spontaneous mEPSCs (i.e., in $2 \mathrm{~min}$ ) and evoked mEPSCs (i.e., in 50 sweeps), respectively. The increase in frequency of both spontaneous and evoked mEPSCs during development may reflect an increase in the number of release sites as maturation progresses (Iwasaki and Takahashi, 2001; Taschenberger et al., 2002), consistent with previous studies that showed a developmental increase in the size of the AMPAR EPSC (Chuhma and Ohmori, 1998; Futai et al., 2001; Joshi and Wang 2002). When the decay time constants $(\tau)$ of evoked mEPSCs under both control (Fig. 2F) and $\mathrm{Sr}^{2+}$ (Fig. 2G) conditions were compared, we found that $\tau$ values of $<\mathrm{P} 10$ synapses $\left(0.56 \pm 0.03 \mathrm{msec}\right.$ in $\mathrm{Ca}^{2+}$; $0.58 \pm 0.05 \mathrm{msec}$ in $\mathrm{Sr}^{2+}$ ) are significantly longer than that of $>$ P12 synapses $\left(0.38 \pm 0.02\right.$ msec for both $\mathrm{Ca}^{2+}$ and $\left.\mathrm{Sr}^{2+}\right)$. On the contrary, evoked mEPSCs over the same developmental window showed little change in their size (Fig. $3 H$ ), suggesting that the number of release sites but not the quantal size likely accounts for the increase in the synaptic strength throughout development. On the basis of these experiments, we confirm that shortening of the decay time course of unitary quantal events underlying evoked AMPAR EPSCs does indeed occur independent of the asynchrony of fusion events. Such developmental changes in the decay kinetics of the AMPAR EPSCs may be attributed to postsynaptic elements governing AMPAR channel gating.

\section{AMPARs devoid of GluR2 mediate synaptic transmission during development}

AMPARs that contain the GluR4 subunit may mediate fast synaptic transmission in rat and chick auditory synapses (Geiger et 
al., 1995; Otis et al., 1995; Zhou et al., 1995; Wang et al., 1998; Caicedo and Eybalin, 1999; Ravindranathan et al., 2000). We postulated that during development, the AMPAR complex might switch from subunits that are slow gating and $\mathrm{Ca}^{2+}$ impermeable to fast-gating $\mathrm{Ca}^{2+}$ permeable compositions (e.g., from GluR2 to GluR4), leading to the accelerated decay time course. $\mathrm{Ca}^{2+}$-permeable AMPARs, devoid of GluR2 in the channel complex, are known to be blocked by intracellular polyamines, such as spermine, which causes a characteristic inward rectification of the $I-V$ curve at positive holding potentials (Bowie and Mayer, 1995; Donevan and Rogawski, 1995; Kamboj et al., 1995). To study the biophysical properties of synaptic AMPARs, we included spermine $(100 \mu \mathrm{M})$ in the intracellular pipette and recorded AMPAR EPSCs from synapses of different developmental stages. Because the peak time of NMDAR EPSC and AMPAR EPSC clearly differs (Fig. 1), we did not include MK-801 for this set of experiments. Figure $3 A$ contrasts recordings from P5 and P14 synapses in the absence and presence of intracellular spermine. The fast AMPA component of the EPSC typical at +60 $\mathrm{mV}$ was absent when spermine was included in the intracellular solution regardless of the developmental age. This was further illustrated in the $I-V$ curves (Fig. 3B) where there was a strong inward rectification at positive holding potentials in the presence of spermine for all ages. In contrast, linear $I-V$ curves were produced when the intracellular solution did not contain spermine, presumably because of rapid dialysis of endogenous polyamines from the recorded cells. We quantified these observations by calculating the rectification index using the ratio between the current amplitude at +60 and -60 $\mathrm{mV}$. In the absence of added spermine, the rectification index of $\mathrm{P} 14$ synapses was slightly higher than that of P5 synapses $(p>0.05)$, but AMPAR EPSCs were equally rectified when spermine was included (Fig. 3C). These observations suggest that GluR2 unlikely contributes to the channel complex of synaptic AMPARs and these receptors are likely $\mathrm{Ca}^{2+}$ permeable throughout development of this synapse.

We next examined whether the onset of rectifying AMPARs within MNTB neurons takes place before or after synaptogenesis. We recorded whole-cell currents evoked by the exogenous AMPAR agonist kainate $(300 \mu \mathrm{M})$ from MNTB neurons before synaptic innervation $(<\mathrm{P} 4 / 5)$. Be-
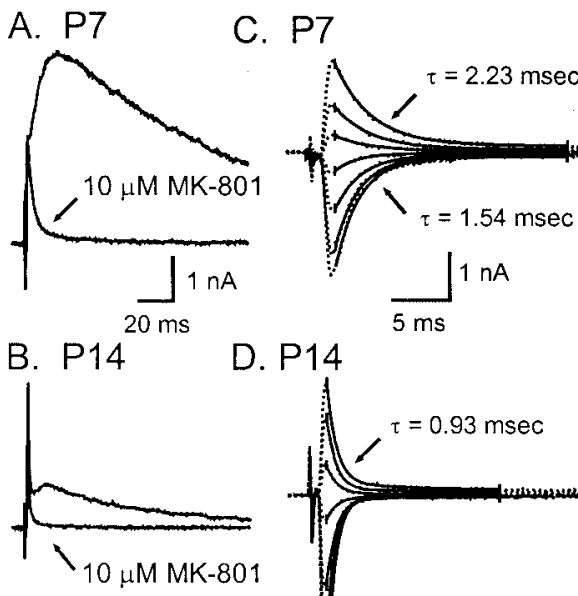

D. P14

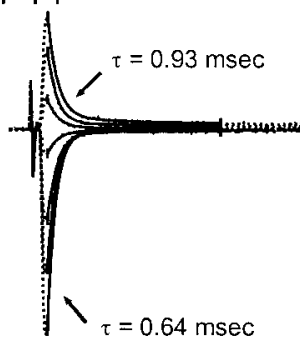

G. Spontaneous minis in MK801
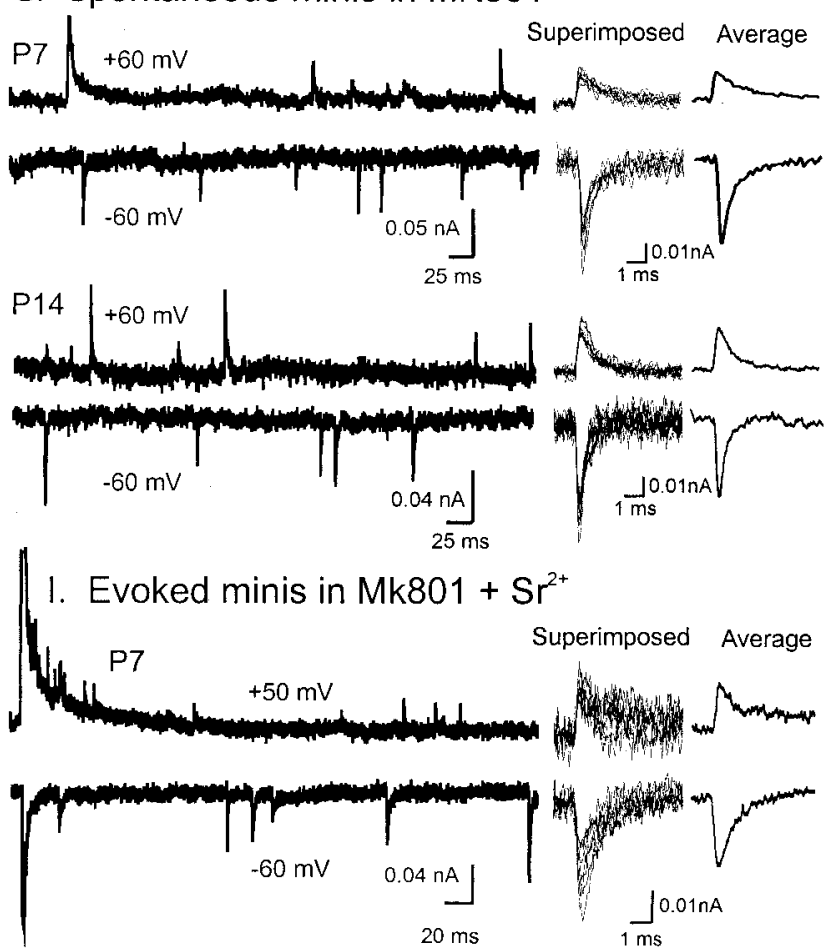

J.

$\mathrm{H}$.
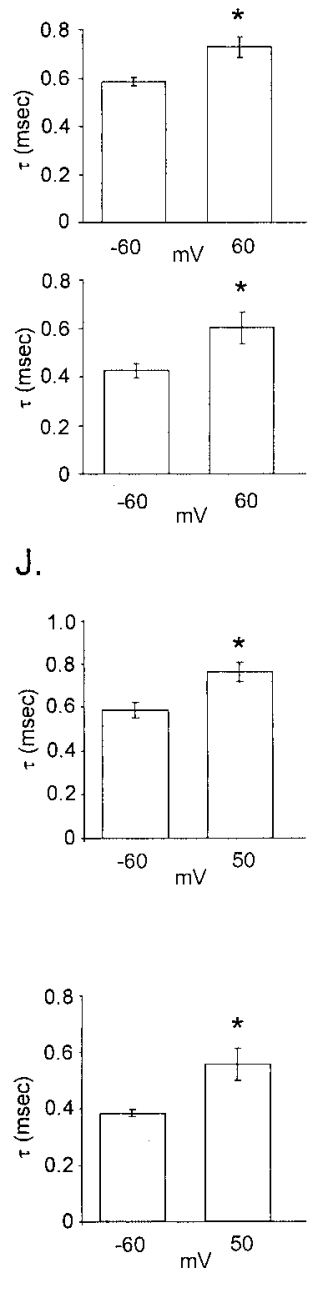

Figure 1. AMPAR EPSC decay kinetics and voltage dependence. $A, B$, Superimposed traces show that the slow NMDA component of EPSCs recorded in control at $+60 \mathrm{mV}$ is blocked by MK- 801 (10 $\mu \mathrm{M}$; arrows) in both P7 $(A)$ and P14 ( $B$ ) synapses, leaving only the fast AMPA component. C, D, AMPAR EPSCS (dotted lines) recorded in the presence of MK-801 at different holding potentials ( +60 to $-60 \mathrm{mV}$ in $20 \mathrm{mV}$ increments) for a P7 ( $($ ) and P14 (D) synapse are shown. Decay phase was fitted with a single exponential function (solid lines), and $\tau$ values for $\pm 60 \mathrm{mV}$ are given. $E, \tau$ values of AMPAR EPSCs were plotted against holding potentials. Note that the voltage dependence of decay kinetics was well described by linear regression to $\tau$ values at different hold- 
cause kainate can activate both synaptic and extrasynaptic AMPARs without causing marked desensitization in MNTB neurons (Joshi and Wang, 2002), we performed voltage ramps ( -60 to $+60 \mathrm{mV})$ at the plateau of kainate-induced inward current (holding potential, $-20 \mathrm{mV}$ ). Figure $3 D$ (left panel) shows whole-cell ramp responses recorded from P3 neurons in the absence and presence of spermine. Spermine clearly induced a strong inward rectification at positive holding potentials when compared with control currents, suggesting that functional AMPARs appear on the membrane surface of MNTB neurons before synaptic contact is made. These receptors are likely $\mathrm{Ca}^{2+}$ permeable from the initial stages of development. Similarly, there was a strong inward rectification of kainate-evoked currents in older neurons (P12) (Fig. 3D, right panel). The rectification ratio values with or without spermine were virtually identical for both age groups (Fig. 3E). Because kainate activates both synaptic and extrasynaptic AMPARs, inward rectification of kainate currents indicates a negligible contribution of the GluR2 subunit to either the synaptic or extrasynaptic AMPAR channel complexes in the postsynaptic MNTB cell.

To directly test whether GluR2 is an integral component of synaptic AMPARs, we used a class of polyamine compounds that selectively blocks AMPARs lacking the normally edited GluR2 subunit (Washburn and Dingledine, 1996; Washburn et al., 1997; Bahring and Mayer, 1998). The synthetic polyamine HPP-SP has been shown to block synaptic AMPARs in a use-dependent manner in hippocampal glutamatergic synapses of GluR2 knock-out mice (Mainen et al., 1998). Figure $3 F$ displays EPSCs before and after extracellular HPP-SP application $(20 \mu \mathrm{M})$ to a P14 synapse. To facilitate block, we applied short trains of stimuli (100 msec, $100 \mathrm{~Hz}$, intertrain interval $20 \mathrm{sec}$ ). In control experiments, such stimulation led to a $27 \%$ rundown in current amplitude over 35 $\min$ (to $73 \pm 1.7 \%$ of the initial amplitude). After HPP-SP application, however, we found a significant block in the amplitude of EPSCs (43\%) (to $30 \pm 0.8 \%$ of the initial amplitude). The blockade developed slowly (15-20 $\mathrm{min}$ ) in a use-dependent manner as illustrated by the amplitude plot of the first EPSC in the train (Fig. $H)$. In contrast to the results with intracellular spermine, we observed that the HPP-SP induced block of AMPAR EPSCs is not strongly voltage dependent (Fig. $3 G$ ), raising the possibility that there may be a second spermine binding site that may reside outside the membrane electrical field. Although it is unknown whether single or multiple GluR2 subunits are required to confer the channel complex insensitivity to spermines, our findings with internal and external spermine block suggest that the GluR2 subunit is not a major contributor of the channel pore of synaptic AMPARs. This suggests that perhaps subunit switching among other GluRs may underlie developmental changes in the accelerated decay kinetics of AMPAR EPSCs in this synapse.

\section{Shift in the relative abundance between GluR1 and GluR3/4}

To establish the molecular correlates to our observed electrophysiological responses throughout development, we used subunit-specific antibodies to determine the expression levels of AMPA subunits GluR1-4 (Fig. 4). Peroxidase staining of the MNTB region from three age groups (i.e., P5/6, P9/10, and P18-20) are shown in Figure $4 A$. Pixel intensities of cytoplasmic staining on individual MNTB neurons were used as an indicator of subunit expression levels in individual neurons (Fig. 4B). The overall somatic expression of GluR1-4, with GluR1 in particular, decreased over the initial 3 postnatal weeks. GluR2 was weakly expressed at all ages, which is consistent with the intracellular and extracellular spermine studies described above. This further confirms that GluR2 unlikely contributes to developmental changes in the kinetic properties of AMPA receptors. Because of the low expression levels of GluR2, the percentage increase in pixel intensities calculated for sections treated with the GluR2/3 antibody can be taken as a measure of GluR3 expression levels. Because GluR1, GluR3, and GluR4 are expressed at all examined developmental stages, the relative abundance of each subunit may determine the gating phenotypes of AMPAR EPSCs. Analogous suggestion was made on the basis of results from single-cell PCR analyses of relative abundance of GluR subunit mRNA expression levels (Geiger et al., 1995). Although these subunit expression patterns share some degree of similarity to that in rats (Caicedo and Eybalin, 1999), we have noted a number of differences in our study on mice (see Discussion). In light of our observations in the developing mouse calyx of Held synapse, we suggest that GluR1 dominates the slow gating kinetics of AMPAR EPSCs in immature synapses. The relative abundance of GluR3/4 to GluR1 may dictate the faster decay time course of AMPAR EPSCs in mature synapses.

\section{Gating kinetics of AMPARs in developing MNTB neurons}

The calyx of Held synapse undergoes dramatic morphological transformations over the first two postnatal weeks (for review, see von Gersdorff and Borst, 2002). The spoon-shaped calyx at early postnatal stages may prevent glutamate from being removed rapidly, whereas mature finger-digit-like terminal allows rapid clearance of glutamate from the synaptic cleft. Although our immunohistochemical results suggest that there is a shift in AMPAR subunit composition, it remains possible that a difference in the residence time of glutamate in the synaptic cleft may influence the decay kinetics of AMPAR EPSCs during development. To directly address this issue independent of confounding presynaptic factors, we examined the gating kinetics of AMPARs in outside-out patches pulled from immature and mature MNTB neurons in acute slices (i.e., P6-8 vs P13-15). To accurately delineate the time course of deactivation and desensitization, we used a piezoelectric perfusion system to achieve ultrafast application of glutamate to the excised patches. The decay time course of the recorded current evoked by a brief transient of glutamate (e.g., 1-2 msec) is thought to reflect the kinetics of channel closing (i.e., deactivation) because agonist could be removed rapidly before open AMPAR channels enter the desensitized state. Alternatively, a prolonged application of glutamate (e.g., $100 \mathrm{msec}$ ) forces the transition of AMPARs from the open state to the closed

\section{$\leftarrow$}

ing potentials and that P14 synapses $(n=6)$ have much smaller $\tau$ values than P7 synapses $(n=6)$ at any given voltage. $F$, The $\tau$ value at any given holding potential was normalized to that at $+60 \mathrm{mV}$ for both P14 and P7 synapses in $E$ and replotted, and linear regression of these two sets of data gives similar slopes. G, Sample traces of spontaneous $\mathrm{mEPSCS}$ (minis) recorded from a P7 and a P14 $(n=7)$ synapse at -60 and $+60 \mathrm{mV}$ in the presence of MK-801 $(10 \mu \mathrm{M})$ are shown. Right panel displays superimposed raw traces and averaged traces of individual events at +60 and $-60 \mathrm{mV}$. H, A summary plot of $\tau$ values obtained from P7 $(n=6)$ and P14 synapses $(n=7)$ at -60 and $+60 \mathrm{mV}$, showing faster decay time course at $-60 \mathrm{mV}$ than at $+60 \mathrm{mV}$. I, Traces of evoked mEPSCs after a compound response (graphically truncated) recorded in a mixture of MK- 801 and $\mathrm{Sr}^{2+}$ at +50 and $-60 \mathrm{mV}$ for P7 and P14 synapses. Superimposed raw and averaged traces of individual events at +50 and $-60 \mathrm{mV}$ are shown in the right panels as in $G$ for evoked mEPSCs. J, A summary plot of $\tau$ values at +50 and $-60 \mathrm{mV}$ for both P7 $(n=6)$ and P14 synapses $(n=6)$. Statistic difference ( $p<0.05$; Student's $t$ test) is indicated by asterisk in this and subsequent figures. 
state in the continuous presence of agonist (i.e., desensitization). For our purposes of characterizing deactivation and desensitization, we chose to apply a high concentration of glutamate $(10 \mathrm{~mm})$ to the same patches for 1 and $50 \mathrm{msec}$, respectively. Figure $5 A$ shows two such examples of averaged ensemble responses recorded from patches of P6 and P14 MNTB neurons. In response to both types of glutamate application, patches from a P6 neuron displayed significantly slower decay than that from P14 neuron. The time constants $(\tau)$ derived from single exponential fits to the decay phase of these responses are summarized in Figure 5B, illustrating a significant acceleration in both deactivation and desensitization kinetics over this developmental window. Mean $\tau$ values for deactivation and desensitization as well as relative differences between these two parameters are significantly higher in patches from $\mathrm{P} 6-8$ neurons (i.e., $1.35 \pm 0.12$ and $2.6 \pm 0.23$ msec) than that from P13-15 neurons (i.e., $0.81 \pm 0.07$ and $1.13 \pm 0.05 \mathrm{msec}$ ) (Fig. 5B). Consistent with our immunohistochemical results postulating a developmental subunit shifting from slow GluR1-dominant to fast GluR3/4dominant gating channels, these $\tau$ values are in line with those in the literature showing that desensitization and deactivation kinetics of homomeric GluR1 are much slower than homomeric GluR3/4 channels (for review, see Dingledine et al., 1999).

In recombinant expression systems, homomeric GluR1 channels exhibit much slower recovery kinetics from desensitization than GluR3/4 channels (Dingledine et al., 1999). If there were a shift in relative abundance of GluR3/4 over GluR1 in developing MNTB neurons as we postulated, one would predict recovery from desensitization to follow a different time course for AMPARs in immature and mature neurons. To test this prediction, a dual-pulse application protocol was used. The first pulse of glutamate (pulse duration, $25 \mathrm{msec}$ ) was used to desensitize AMPARs in the patch, and then a second pulse was applied at increasing interpulse time intervals to measure the extent of recovery. Figure $5 C$ contrasts two such experiments with patches from P6 and P13 neurons, respectively. In both cases, the first pulse desensitized AMPARs by $>90 \%$, but recovery from desensitization in the former is evidently slower. When the amplitude of the second response was normalized to that of the first in the same sweep and plotted against the interpulse time interval (Fig. $5 D$ ), we found that recovery kinetics for patches from both age groups could be well described by a single exponential function with the time constant of $\sim 63 \mathrm{msec}$ for $\mathrm{P} 6-8$ patches and $\sim 28$

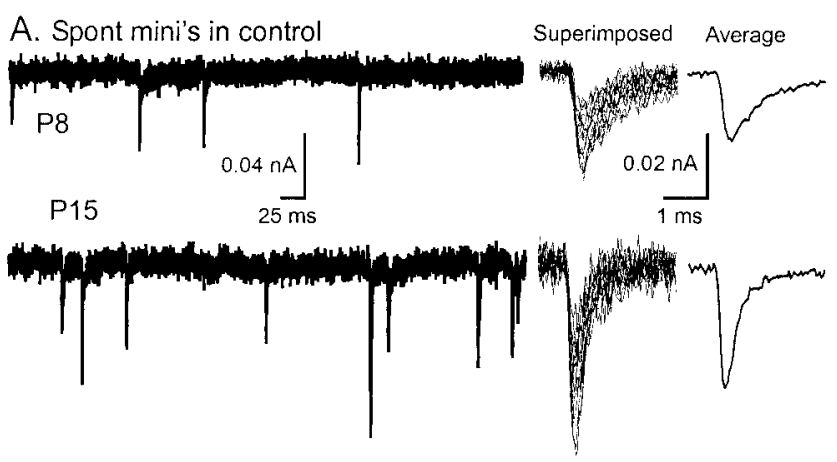

B. Spont mini's in control
C. Evoked mini's in control

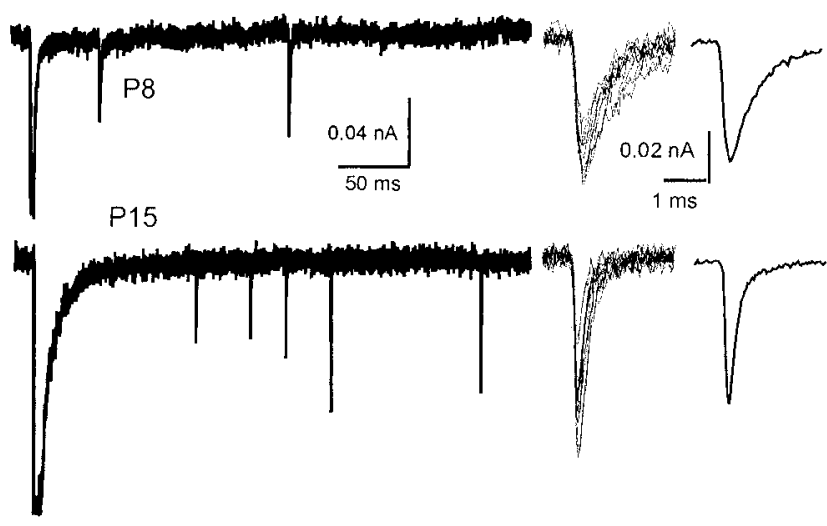

D. Evoked mini's in $\mathrm{Sr}^{2+}$
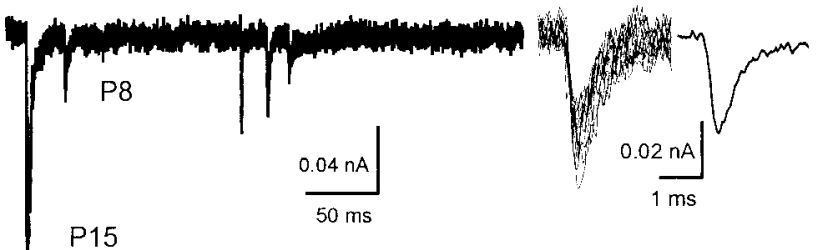

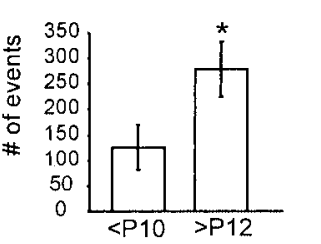

E. Evoked mini's in $\mathrm{Sr}^{2+}$

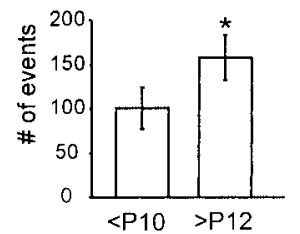

F. Evoked mini's in control

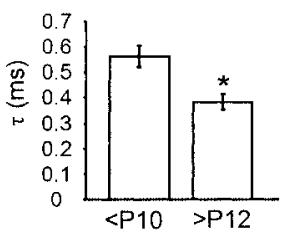

G. Evoked mini's in $\mathrm{Sr}^{2+}$

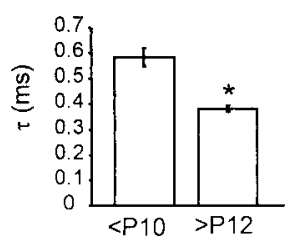

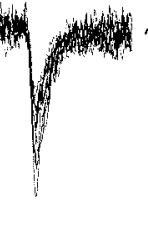

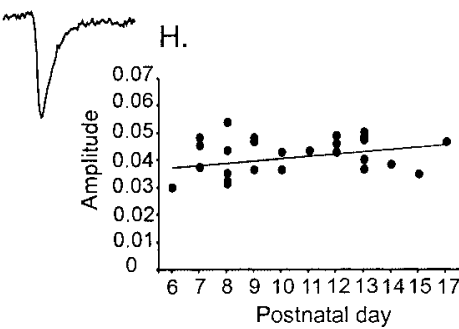

Figure 2. Age-dependent changes in properties of unitary quantal events underlying evoked AMPAR EPSCS. A, C, D, Traces of spontaneous $(A)$, evoked mEPSCs in $\mathrm{Ca}^{2+}(C)$ and Sr ${ }^{2+}(D)$ recorded at $-60 \mathrm{mV}$ for the same P8 and P15 synapses. Superimposed raw traces and averaged traces of individual events are shown (right panels). B, E, Plots of the total number of spontaneous $m E P S C s$ in $2 \mathrm{~min}(B)$ (in $\mathrm{Ca}^{2+}$ ) or evoked mEPSCs in 50 sweeps $(E)$ (in $\mathrm{Sr}^{2+}$ ), showing more frequent events in older synapses $(>P 12)$ when compared with younger ones ( $<P 10) . F, G$, Comparison of $\tau$ values for evoked mEPSCs collected in $2 \mathrm{~mm} \mathrm{Ca}^{2+}(F)$ or Sr${ }^{2+}$ (G). $\mathrm{H}, \mathrm{A}$ scattered plot of quantal amplitude against the age of all recorded synapses (evoked $\mathrm{mEPSCs}$ in $\mathrm{Sr}^{2+}$ ), showing that developmental changes in decay time course were independent of the average quantal size.

msec for P13-15, respectively. The latter is consistent with that of homomeric GluR3/4 channels, whereas the former is significantly lower than that of homomeric GluR1 channels $(\sim 150$ $\mathrm{msec}$ ) (Dingledine et al., 1999). This observation indicates that there may be an incorporation of GluR3/4 into the GluR1-dominant AMPAR channel complex in native MNTB neurons at P6-8, leading to faster recovery kinetics than GluR1-only AMPARs. This result is consistent with our immunohistochemical data showing expression of GluR3/4 in MNTB neurons at this developmental stage. 


\section{Intracellular Spermine}

A. EPSCs

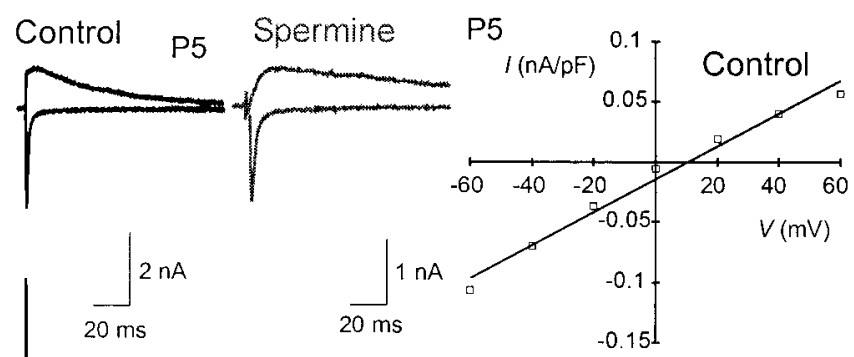

P14

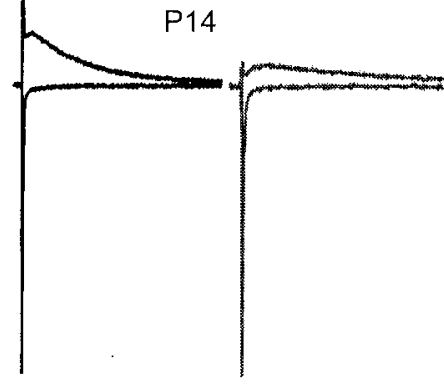

$\mathrm{P} 14$
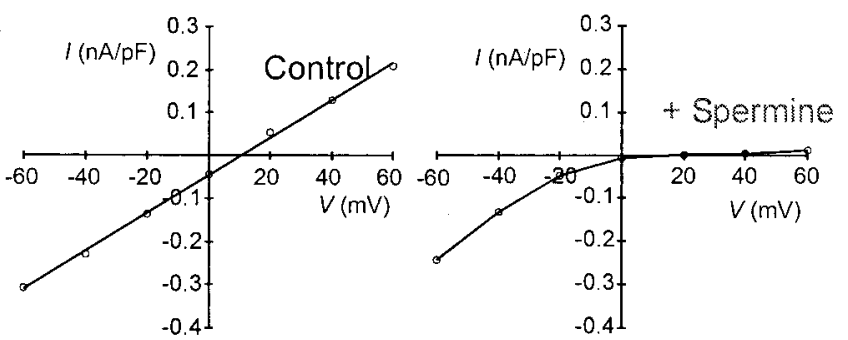

D. Kainate Whole-cell Currents P3
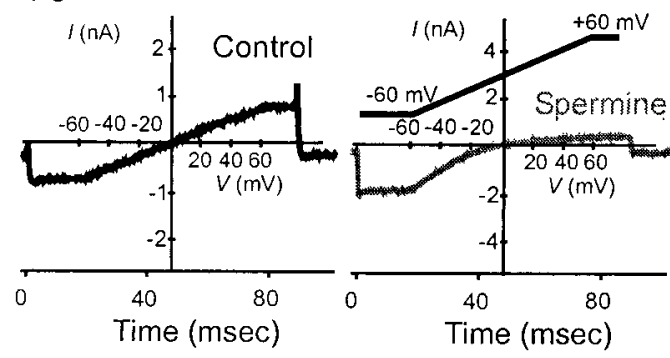

$\mathrm{P} 12$

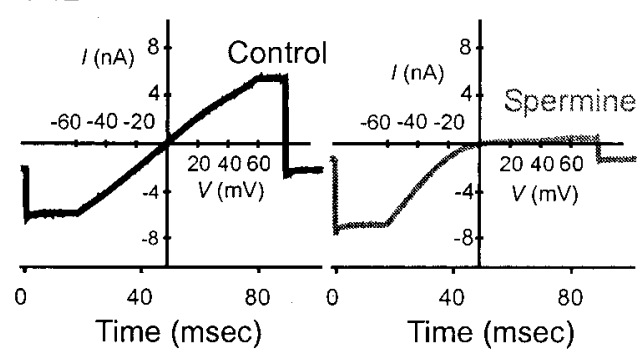

\section{Rectification indices}
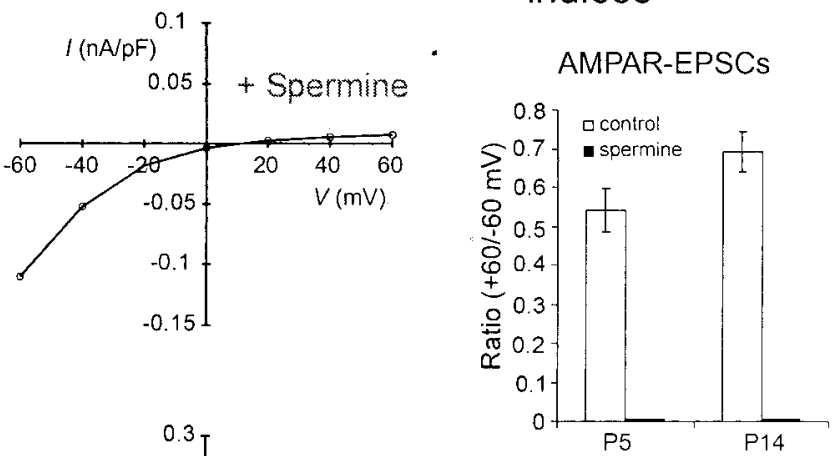

\section{E. Rectification indices}

Kainate whole-cell currents

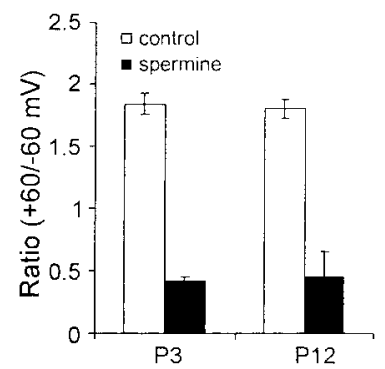

\section{Extracellular Spermine}

F.

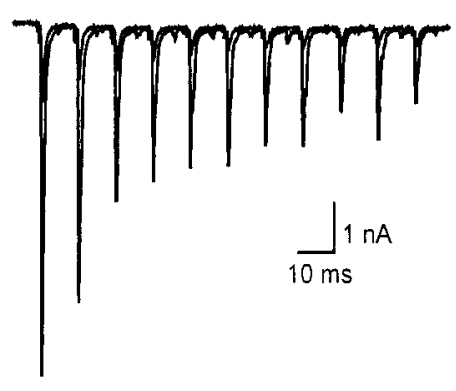

G.

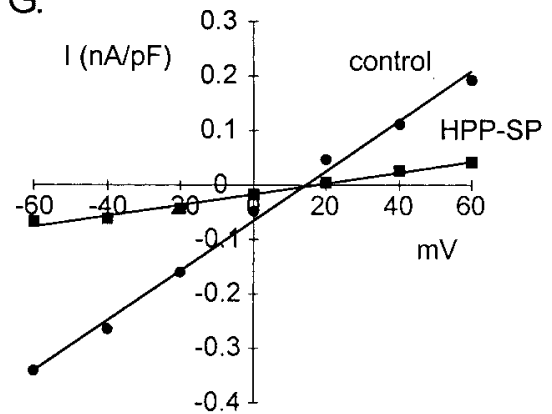

H.

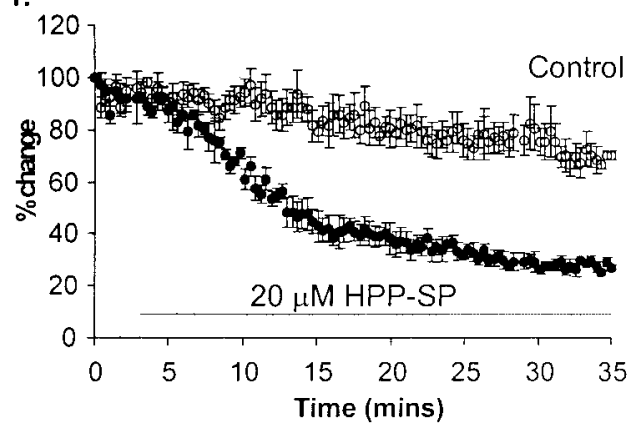

Figure 3. Blockade of AMPARs by intracellular and extracellular spermines. A, Comparison of EPSCs ( $+60 \mathrm{vs}-60 \mathrm{mV}$ ) recorded at P5 (top panel) and P14 (bottom panel) synapses in the absence (left) and presence (right) of $100 \mu \mathrm{m}$ intracellular spermine. B, Current-voltage ( - - V relationships for AMPA EPSCs in control (left panel) and spermine (right panel) for P5 and P14 synapses shown in $A$. Note the significant rectification of the curve at positive potentials in the presence of spermine. $D$, Examples of whole-cell ramp currents ( -60 to $+60 \mathrm{mV}, 100 \mathrm{msec}$ ) recorded in the presence of kainate $(0.3 \mathrm{~mm})$ for $\mathrm{P} 3$ and $\mathrm{P} 12$ neurons with (to right) and without (to left) spermine. Holding potential was $-20 \mathrm{mV}$, and leak currents were determined using the same ramps before kainate application and subtracted. Note recordings in the absence and presence of spermine shown in $A$ and $C$ are from separate cells in each age group. C, E, Bar plots summarizing rectification indices (i.e., the ratio between current amplitude at +60 and $-60 \mathrm{mV}$ ) for AMPAR EPSC $I-V$ curves and kainate whole-cell currents as in $B$ and $D$. Results from six to eight synapses for each experimental condition were pooled for different age groups. $F$, Traces collected, in a P14 synapse, before and after application of extracellular HPP-SP (20 $\mu$ M) are superimposed to show that AMPARs are blocked after repeated short train stimuli (100 msec at $100 \mathrm{~Hz} ; 20$ sec intertrain intervals). G, I-V curves for AMPA EPSCs in control and after HPP-SP blockade. Note that this block is not strongly voltage dependent. $H$, A plot of the normalized peak amplitude of the first EPSC of the train against time in the absence (open circles; $n=4)$ and presence (closed circles; $n=4$ ) of HPP-SP. The current amplitude of the EPSC at any given time was normalized to that at time 0 . Note that high-frequency stimulation caused only a $27 \%$ rundown in current amplitude under control conditions, whereas there was an additional block of the current (43\%) in the presence of HPP-SP. 
A.
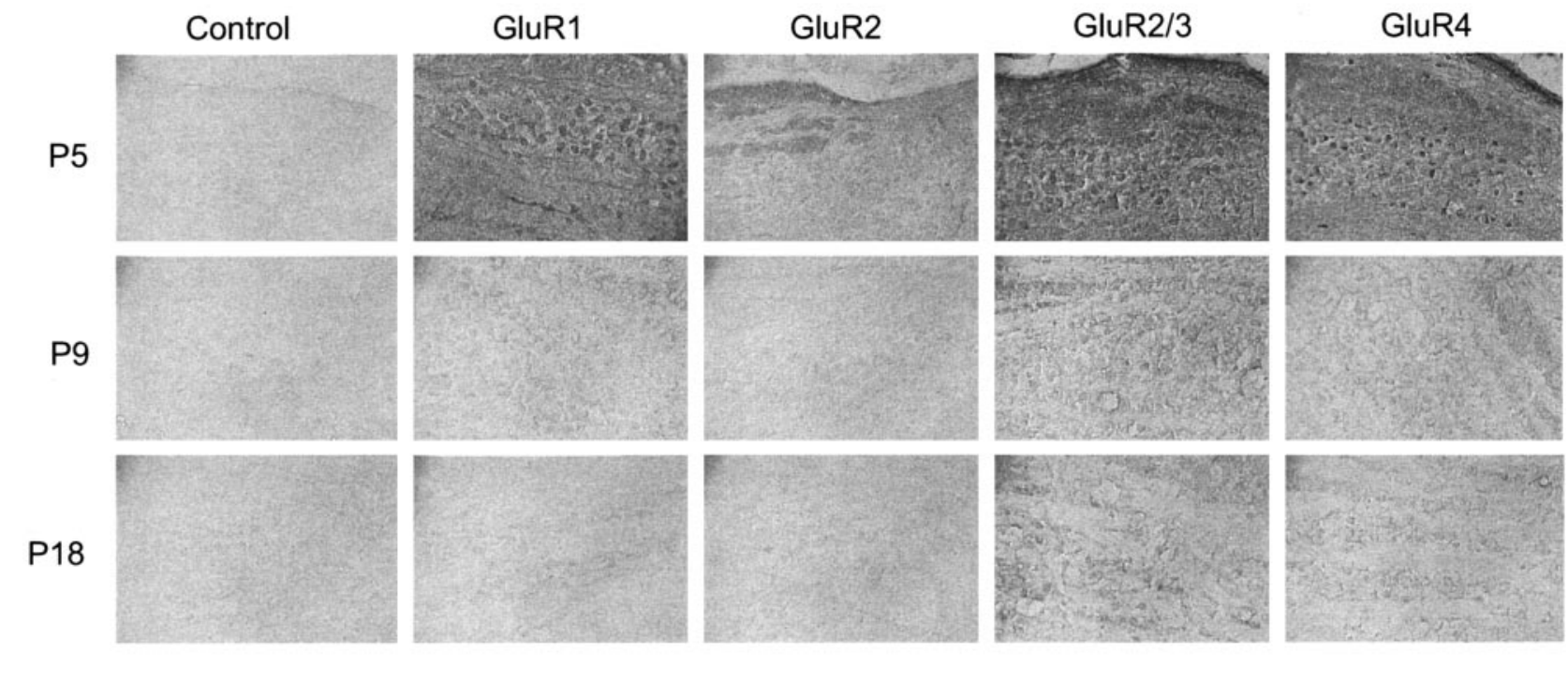

B.

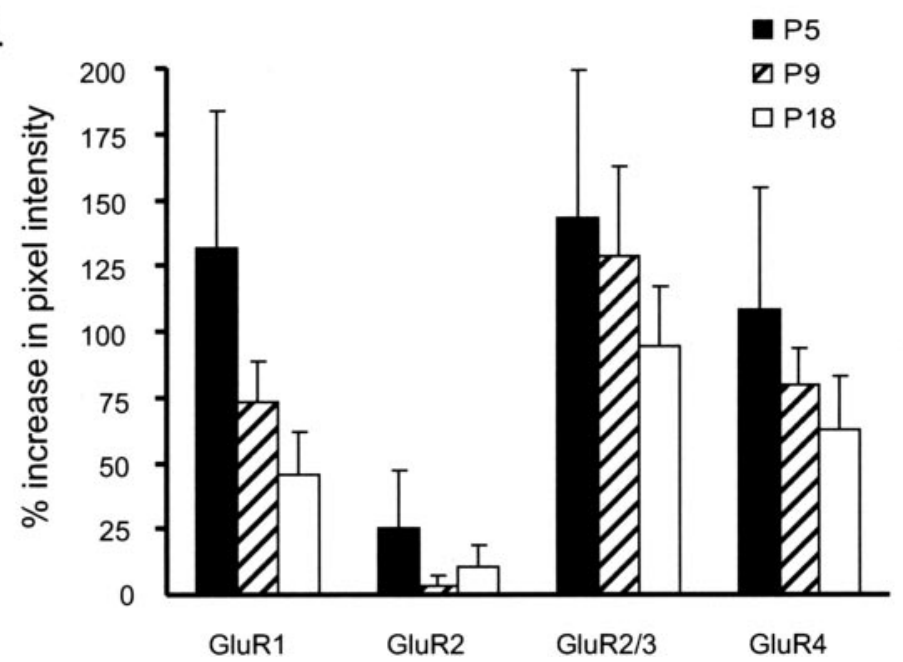

Figure 4. Developmental changes in expression levels of AMPARs. A, Staining patterns produced by antibodies reactive to the mouse GluR1, GluR2, GluR2/3, and GluR4 subunits (from left to right) in P5, P9, and P18 synapses. Control sections underwent the same staining procedures except for the treatment with a primary antibody. B, The surface expression levels of AMPARs were normalized and plotted as a measure of the percentage increase in average pixel intensity from control slides. Note the low level of GluR2 expression and sharp decline in GluR1 during development.

\section{Contribution of accelerated decay kinetics to high-frequency firing}

Along with morphological refinements of the calyx of Held synapse during early postnatal stages, there are also profound changes in biophysical properties that lead to the capacity for high-fidelity neurotransmission across the synapse (von Gersdorff and Borst, 2002). Many presynaptic and postsynaptic modifications often occur concurrently. For example, in response to high-frequency stimulation, synaptic depression is robust in immature synapses (Borst and Sakmann, 1996; von Gersdorff et al., 1997; Joshi and Wang, 2002), and the extent of this depression as well as the number of failures decrease as synapses mature, whereas recovery from synaptic depression accelerates (Joshi and Wang, 2002). Therefore, assessing the contribution of a single parameter such as accelerated decay kinetics to the capability of this synapse to accommodate high-frequency firing is challenging. To isolate the functional role of speeding decay kinetics of AMPAR EPSCs, we have chosen to use older synapses $(>P 14)$ in which many of the synaptic properties have reached maturity. By selectively prolonging the decay kinetics of AMPAR EPSCs using a pharmacological approach, one can mimic the developmental changes in this one particular parameter and address its role in high-frequency synaptic transmission, independent of other confounding factors. We chose cyclothiazide (CTZ), an AMPAR desensitization blocker, to prolong the decay of the EPSC to the same extent as that of a young synapse (Fig. 6A). A low concentration of CTZ $(30 \mu \mathrm{M})$ was used to minimize its presynaptic actions at this synapse (Ishikawa and Takahashi, 2001). Previous work done in mature calyx of Held synapses ( $>$ P13 age group) from our lab and others (Wang and Kaczmarek, 1998; Joshi and Wang, 2002; Taschenberger et al., 2002) has shown that neither the extent nor the pattern of synaptic depression in a train is significantly altered by CTZ. Indeed, CTZ produced only slight changes in the amplitude of the EPSC, whereas the decay time course of the AMPAR EPSC was prolonged to such an extent as that found in P6/7 synapses. Under current-clamp conditions, we 
A.

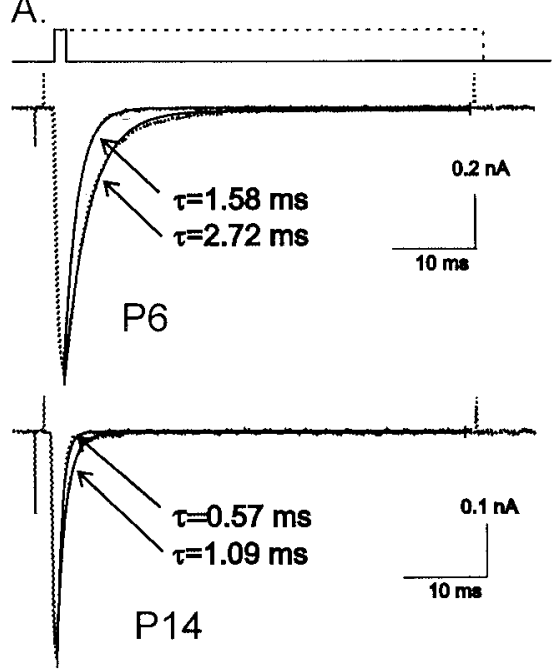

B.

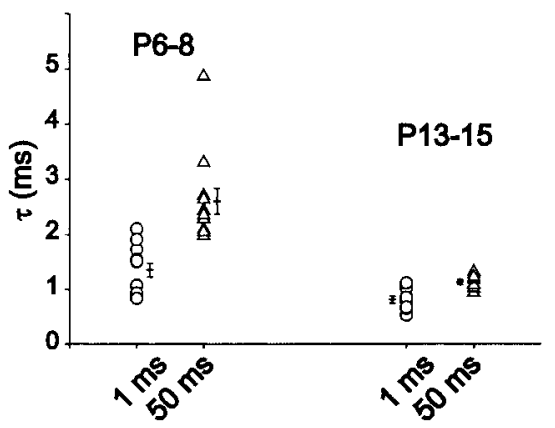

C.
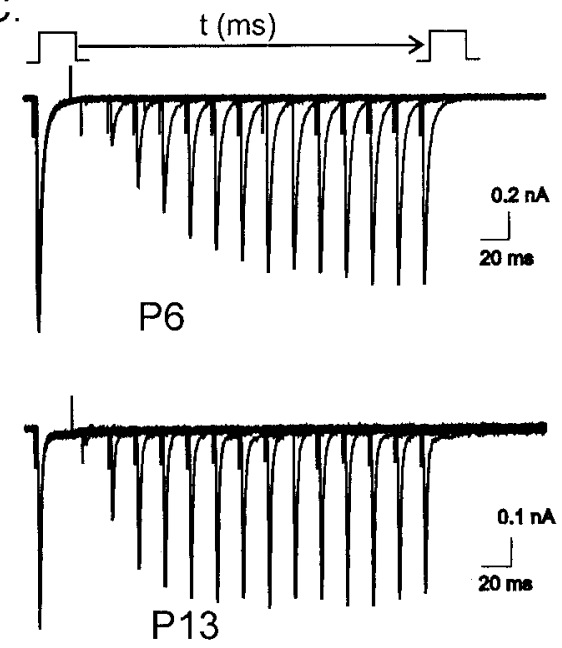

D

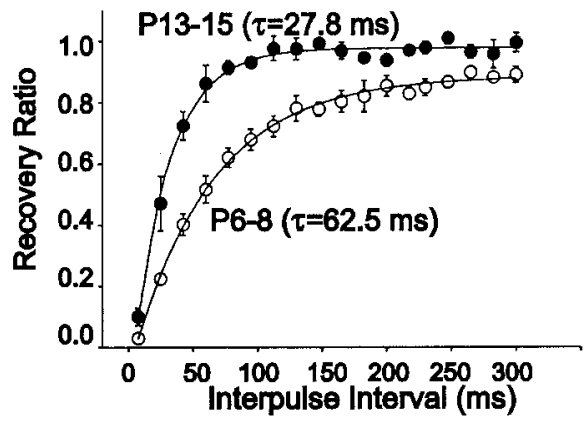

Figure 5. Kinetic properties of AMPARs in outside-out patches of developing MNTB neurons. A, Examples of currents (dotted lines) recorded from outside-out patches of P6 (top panel) and P14 (bottom panel) MNTB neurons. Responses to 1 or 50 msec single-step applications of glutamate $(10 \mathrm{~mm})$ are superimposed, and solid lines are single exponential fits to the decay phase of recorded currents, and time constants $(\tau)$ are given. $B, A$ plot of $\tau$ values for deactivation (open circles) and desensitization (open triangles) (1 vs 50 msec application) in all patches from P6 - $8(n=10)$ and P13-15 $(n=8)$ neurons. The average values for each group of data are indicated by the cross symbol in parallel with scattered data. C, Two typical examples showing superimposed current traces in P6 (top panel) and P13 (bottom panel) patches in response to a two-pulse (25 msec each) application protocol with varying interpulse time interval $(7.5-300 \mathrm{msec})$. $D$, Recovery time courses from desensitization are shown for patches from P6-8 (open circles; $n=4$ ) and P13-15 (filled circles; $n=4$ ) neurons. The current amplitude in response to the second application is normalized to that of the first response in each sweep and plotted against the interpulse time. Solid lines are single exponential fits, and $\tau$ values are given. Holding potential was $-60 \mathrm{mV}$ for all of these experiments.

observed no difference in the shape and size of spike evoked by single EPSPs, except for a much greater after-spike depolarization that decayed more slowly in the presence of CTZ compared with control (Fig. 6B). High-frequency stimulation (100 msec at 100 or $200 \mathrm{~Hz}$ ) elicited a train of spikes without any failures under control conditions (Fig. 6C, top panel). Application of CTZ had little effect on the height of the first spike but caused a pronounced use-dependent reduction in the amplitude of subsequent spikes. This action was particularly evident as the stimulating frequency increased from 100 to $200 \mathrm{~Hz}$ (Fig. 6C, middle panel). Such use-dependent reduction is likely a result of a higher plateau potential associated with larger after-spike depolarization in CTZ. We postulated that as a consequence of this plateau potential, voltage-gated $\mathrm{Na}^{+}$and $\mathrm{K}^{+}$channels were partially inactivated, and hence the spike amplitude during repetitive activity was compromised. To test this directly, we injected a hyperpolarizing current at a later stage of the stimulation train to allow these channels to recover from the inactivated state. Figure $6 C$ (bottom panel) shows responses to hyperpolarization current injections $(\sim 1 \mathrm{nA})$ after CTZ exposure for both 100 and $200 \mathrm{~Hz}$ stimulations. Hyperpolarizing current injections indeed brought the plateau potential back to control levels, and spike amplitudes also recovered. On the contrary, a short depolarizing current injection (0.2 $\mathrm{nA}$ ) in the absence of CTZ generated a plateau potential, leading to a decrease in spike size and an increase in spike width (Fig. 6D).

Because CTZ may affect not only gating kinetics of postsynaptic AMPARs but also presynaptic release and various voltage-gated conductances required for spiking, one would ideally examine the effect of slowing EPSC decay on spike firings without using any pharmacological reagent. To this end, we used computer simulations to generate two EPSCs that had the same amplitude ( $5 \mathrm{nA}$ ) but different decay constants (0.65-1.3 msec), typical of those obtained from immature and mature synapses (Fig. 6E). We then performed current-clamp recordings of spikes in mature MNTB neurons, driven by these simulated EPSCs after reversing the polarity of the currents (Fig. 6F). When the decay time constant of the simulated EPSC was prolonged from 0.65 to $1.3 \mathrm{msec}$, we again observed a prominent after-spike depolarization as seen with CTZ. Similarly, a prolongation of decay time course of simulated EPSCs did not affect spike size and shape at $100 \mathrm{~Hz}$ but resulted in a buildup of the plateau potential at $200 \mathrm{~Hz}$, leading to use-dependent changes in the spike size and width (Fig. $6 G)$. Taken together, these two sets of experiments indicate that rapid decay kinetics of AMPAR EPSCs is important for minimizing the plateau potential and ensuring the activation and deactivation of voltagegated conductances required for cell excitability. Hence, subunit switching from slow to fast gating phenotypes during development has important functional implications for the fidelity of neurotransmission at the calyx of Held synapse.

\section{Discussion}

Using a combination of electrophysiological and immunohistochemical analyses, we have examined the mechanisms underlying developmental changes in AMPAR decay kinetics and explored the physiological significance of such changes for high-fidelity neurotransmission at the calyx of Held-MNTB synapse. Our experiments with MK-801 and $\mathrm{Sr}^{2+}$ revealed a genuine voltage and development dependence in the kinetic properties of evoked AMPAR EPSCs and unitary quantal components underlying these EPSCs. Effective block of AMPAR responses by intracellular and extracellular polyamines with signature properties suggests that GluR2 is not a main component of synaptic AMPARs and that the onset of such subunit composition occurs before synaptogenesis. The immunohistochemical staining patterns and the biophysical assays of AMPAR kinetics in outside-out patches 
A.
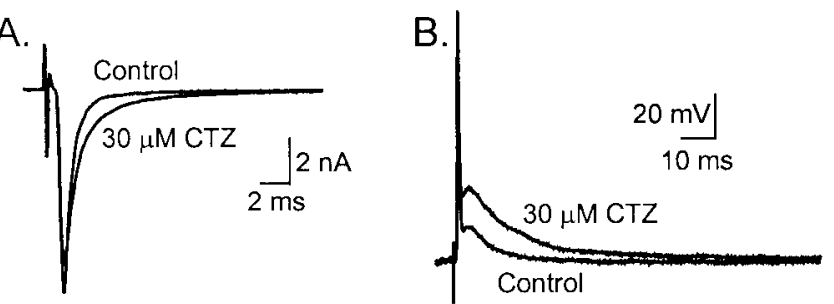

C. Control
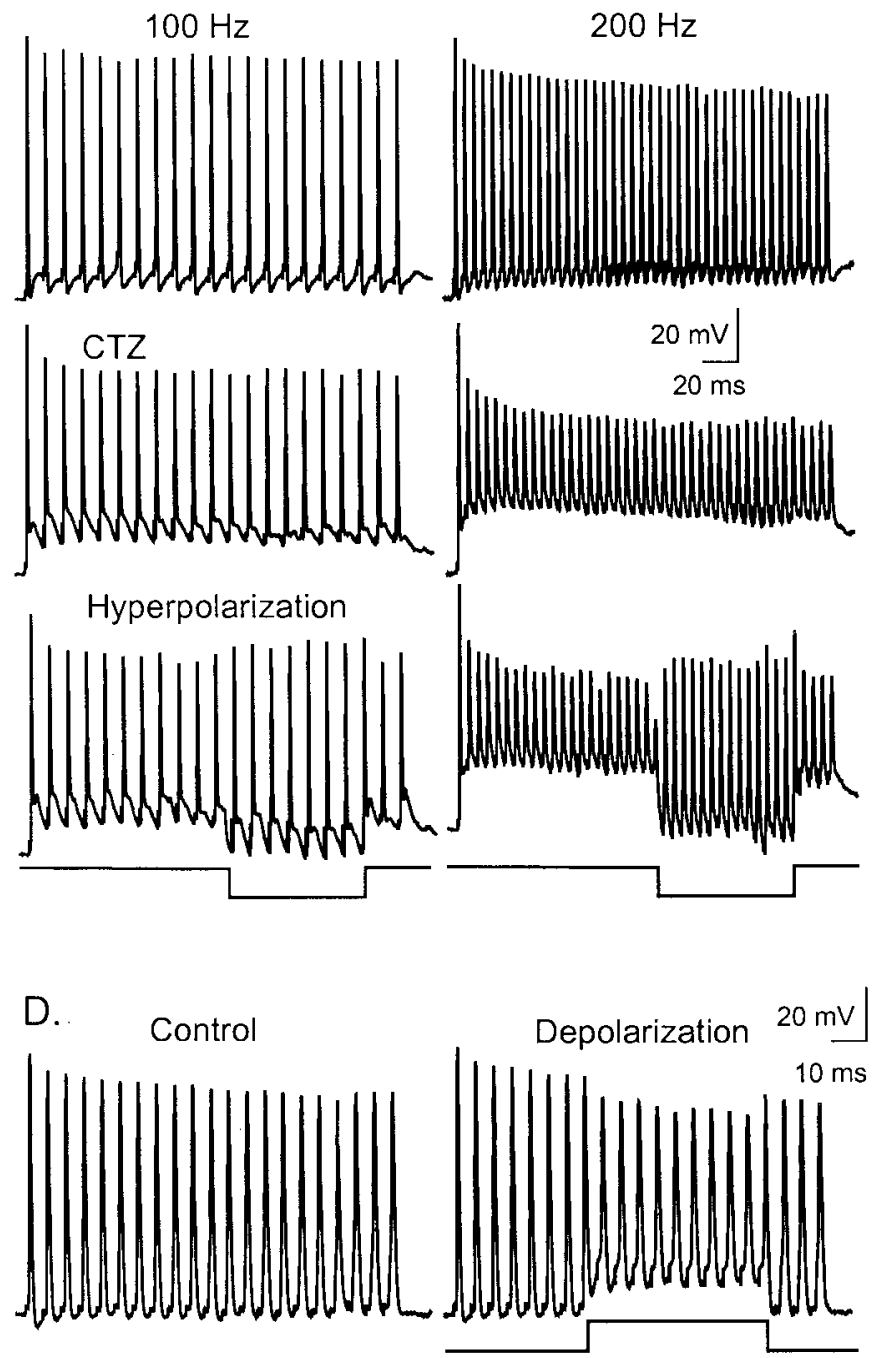

E.

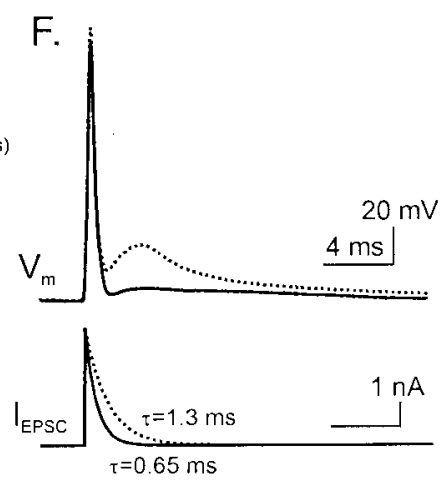

G. Simulated EPSC injections $100 \mathrm{~Hz}$

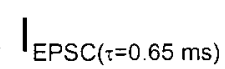
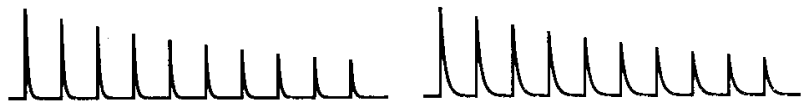

$1 \mathrm{nA}$
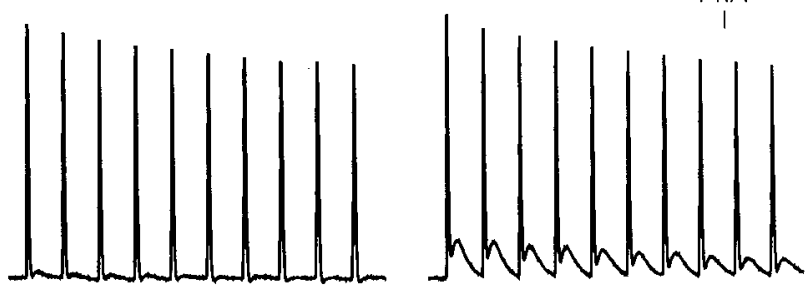

$200 \mathrm{~Hz} \mathrm{I}_{\operatorname{EPSC}(\tau=0.65 \mathrm{~ms})}$

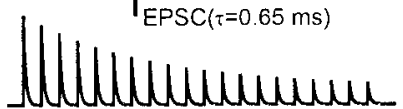

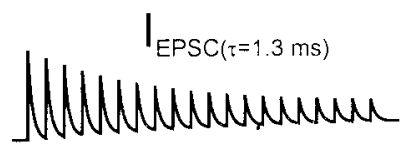

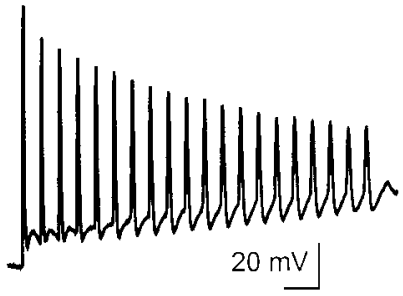

$10 \mathrm{~ms}$

Figure 6. The role of accelerated decay kinetics in high-frequency firing. $A$, Typical EPSCs recorded before and after a low dose of CTZ (30 $\mu \mathrm{M}$ ), showing a prolongation of the decay time course to the same extent as that of an immature synapse. $B$, Current-clamp recordings of spikes evoked by single EPSPs in control and CTZ revealed little difference in shape and size except for a larger after-spike depolarization with the prolonged decay phase in the presence of CTZ. C, Spikes recorded in response to high-frequency train stimulations (200 msec; 100 or $200 \mathrm{~Hz}$ ) under three conditions: control (top panel), CTZ (middle panel), and hyperpolarizing current injection (1 nA) during (TZ-induced plateau potential (bottom panel). Similar observations were made in five other synapses. D, A small plateau potential generated by a short depolarization $(0.2 \mathrm{nA})$ in the absence of CTZ led to use-dependent changes in spike size and shape similar to that in CTZ. Note that this recording was made with a shorter train $(100 \mathrm{msec} ; 200 \mathrm{~Hz})$ to show changes in spike waveform. E, Two simulated EPSCs with identical amplitude ( $5 \mathrm{nA})$ but fast and slow time constant $(0.65 \mathrm{vs} 1.3$ $\mathrm{msec}$ ) are shown. F, Current-clamp recordings of spikes and membrane voltage changes in response to injections of two simulated EPSCs with reversed polarity to that displayed in $E$. G, Spikes recorded in response to the same simulated EPSCs as in G given in 100 and $200 \mathrm{~Hz}$ trains. Note that synaptic depression (Wang and Kaczmarek 1998; Joshi and Wang, 2002) was incorporated into simulated trains in which the EPSC amplitude declined along a single exponential curve with a time constant of $70 \mathrm{msec}$ from initial amplitude of $5 \mathrm{nA}$, and that the only variable altered was the decay time constant. Similar observations were made in four other MNTB neurons. All recordings in this figure were made in the presence of MK-801.

support our suggestion that a developmental alteration in the relative abundance of slow-gating GluR1 versus fast-gating GluR3/4 is potentially important in determining the decay kinetics of AMPAR EPSCs. Finally, we showed that the fast kinetics of AMPAR EPSCs is essential for this synapse to transmit at high rates without compromising spike amplitude. We therefore conclude that kinetic changes in EPSCs are one of the fundamental processes required for maintaining the reliability of synaptic transmission in the calyx of Held-MNTB synapse and preserving timing information for sound localization. 


\section{Mechanisms underlying age-dependent acceleration in AMPAR decay kinetics}

Our observation that AMPAR decay kinetics accelerates during maturation is consistent with that of other studies in auditory synapses (Bellingham et al., 1998; Lawrence and Trussell, 2000; Taschenberger and von Gersdorff, 2000). The decay kinetics of AMPAR EPSCs can be influenced by factors including channel gating, desensitization (Jones and Westbrook, 1996), and the dynamics of glutamate in the synaptic cleft (Jones et al., 1998; Bergles et al., 1999). In this study, we revealed that decay kinetics is also voltage dependent (Fig. $1 E$ ), being faster at negative potentials than positive ones. This phenomenon was independent of the contribution of the slow NMDAR component to the EPSC, which was completely abolished by MK-801 or other competitive and noncompetitive NMDAR antagonists. This was confirmed by comparing decay kinetics of spontaneous and evoked mEPSCs at positive and negative holding potentials. Such voltage dependence may be attributed to the changes in the intrinsic gating properties of channels across which charge-carrying ionic species gradually switched from $\mathrm{Na}^{+}$and $\mathrm{Ca}^{2+}$ ions to $\mathrm{K}^{+}$ions as the holding potentials were advanced from negative to positive potentials. Several previous studies have shown a similar voltage dependence in the gating kinetics of GluRs in outside-out patches taken from both native neurons and recombinant expression cells (Patneau et al., 1993; Raman and Trussell 1995; Bowie et al., 1998). Additional studies are required, however, to fully understand this dependence.

There have been conflicting observations as to the role of asynchrony of events to the developmental changes in the shape of the EPSCs. Chuhma and Ohmori (1998) suggested that asynchrony of fusion events in immature synapses lead to a longer decay time. Other studies demonstrate a developmental reduction in the width of both evoked mEPSCs (in $\mathrm{Cd}^{2+}$ ) (Taschenberger and von Gersdorff, 2000) and spontaneous mEPSCs (Iwasaki and Takahashi, 2001). Our findings agree with the latter studies. Unlike previous studies that examined spontaneous mEPSCs (Chuhma and Ohmori 1998; Iwasaki and Takahashi, 2001), we have used $\mathrm{Sr}^{2+}$ to directly probe the kinetic properties of unitary quantal events that underlie evoked AMPAR EPSCs (Figs. 1, 2). Our approach revealed a marked difference in the gating kinetics of synaptic AMPARs between immature and mature synapses. Furthermore, kinetic properties of AMPARs in outside-out patches from immature and mature neurons are significantly different (Fig. 5). When kinetic properties of AMPARs from these patches (Fig. 5C) are compared with that of synaptic AMPAR EPSCs at $-60 \mathrm{mV}$ from corresponding postnatal stages (Fig. $1 E$ ), we noted that $\tau$ values of deactivation but not desensitization conform with that of EPSCs. Our $\tau$ values are consistent with those of outside-out patches from chick auditory neurons (Raman et al., 1994) and rat MNTB neurons (Geiger et al., 1995) but significantly lower than those from $\mathrm{Ca}^{2+}$-permeable and -impermeable hippocampal neurons (Colquhoun et al., 1992; Koh et al., 1995). Although whether deactivation or desensitization or both govern the time course of EPSCs remains debatable, our results suggest that deactivation gating kinetics of AMPARs is likely the major determinant of the decay time course of AMPAR EPSCs at the calyx of Held synapse. We do not exclude that presynaptic asynchrony of release and postsynaptic desensitization may also make some minor contribution.

Gating switch is required for the development of high-fidelity synaptic transmission

Synaptic transmission in many neurons along the central auditory pathway is mediated by rapidly gating AMPARs (Trussell,
1999), and these receptors contain primarily the GluR3/4 subunits (Petralia et al., 1996; Wang et al., 1998). In addition, it has been reported that flop splice variants are prominent in the MNTB and the chick nucleus magnocellularis (nMag) (Geiger et al., 1995; Ravindranathan et al., 2000). Lawrence and Trussell (2000) suggested that a reduction in flip expression contributes to the developmental changes in AMPAR kinetics in the chick nMag. Other studies using calcium permeability measurements and molecular analysis suggest a low expression level of the GluR2 subunit in the rat and chick auditory neurons (Geiger et al., 1995; Otis et al., 1995; Zhou et al., 1995; Wang et al., 1998; Ravindranathan et al., 2000). This was supported by enhanced spermine sensitivity during early development (Washburn et al., 1997). By using both intracellular and extracellular spermine as a means of measuring the GluR2 subunit contribution to functional receptors (Fig. 3), we found that the GluR2 subunit was virtually absent in the postsynaptic MNTB neuron from early postnatal stages, before calyx terminals contacted their target neuron. Consistent with these results, our immunohistochemistry studies showed very low expression levels of GluR2 at any given postnatal age (Fig. 4). Although the structural determinants of $\mathrm{Ca}^{2+}$ permeability and polyamine block are different (Bowie and Mayer, 1995; Panchenko et al., 1999), a lack of GluR2 in the channel complex usually renders AMPAR $\mathrm{Ca}^{2+}$ permeability. Given the early onset of inward rectification of native AMPARs in MNTB, we suggest that subunit composition devoid of GluR2 in MNTB neurons and perhaps $\mathrm{Ca}^{2+}$ permeability of AMPARs are programmed genetically, independent of synaptic innervation and activity. Our results at this synapse differ from that in the developing chick nMag, where there is a gradual reduction in GluR2 subunit expression as revealed by intracellular spermine block (Lawrence and Trussell, 2000).

Rapidly gating AMPARs with very high levels of GluR3/4 are located in the target cells of the auditory nerve (Hunter et al., 1993; Raman et al., 1994; Wang et al., 1998; Gardner et al., 1999). This is critical for those synapses involved in preserving timing information. In fact, the fusiform cells of the mammalian dorsal cochlear nucleus receive excitatory inputs from both auditory nerve and parallel fibers that express different subunits, but those AMPARs containing the GluR4 subunit are restricted to auditory nerve synapses (Rubio and Wenthold, 1997). Our immunohistochemistry results in the mouse MNTB are generally comparable with those of Caicedo and Eybalin (1999), who have examined developmental profiles of GluR1-4 expression in the rat MNTB. With respect to GluR1/2, both studies showed that GluR1 predominates in immature neurons, whereas GluR2 is weakly expressed throughout the first 3 postnatal weeks. We found high levels, however, of both GluR3 and GluR4 subunits in P5 MNTB neurons in mice, whereas Caicedo and Eybalin (1999) demonstrated low expression of GluR3, and GluR4 is virtually absent until P12 in rat. Our kinetic data of deactivation, desensitization, and recovery from desensitization with outside-out patches (Fig. 5) support the idea that GluR3/4 subunits are part of the AMPAR channel complex in immature MNTB neurons and become predominant as synapses mature. These differences in the expression patterns of GluRs likely reside in the species used for these two studies. It is surprising, however, that the overall expression levels of GluRs (Fig. 4) during development appear to decline, whereas we and others have reported an increase in the amplitude of EPSCs. This discrepancy may be explained by the fact that electrophysiological recordings examine the current density of AMPARs within the synaptic domain, whereas immunohistochemical analysis takes into account the overall somatic levels 
including both synaptic and extrasynaptic AMPARs. Aside from this, there are likely significant increases in the number of presynaptic release sites and postsynaptic receptor clustering in the synaptic domain over this developmental window (Iwasaki and Takahashi, 2001; Joshi and Wang, 2002; Taschenberger et al., 2002).

On the basis of our results and those in the literature, we would emphasize that the developmental changes in the shape of the AMPAR EPSC at the calyx of Held synapse are unlikely caused by a switch-off of one particular subunit, as seen in the cerebellar stellate cell synapses (Liu and Cull-Candy, 2000). Instead, a gradual shift in the relative abundance of fast-gating GluR3/4 over slow-gating GluR1 may account for the speeding of decay kinetics at the calyx of Held-MNTB synapse. Switching of subunit composition seems to be a strategic developmental process in various different brain regions that involve alterations in NMDA, GABA, and glycine receptors (Carmignoto and Vicini, 1992; Takahashi et al., 1992, 1996; Monyer et al., 1994; Tia et al., 1996; Gottmann et al., 1997; Singer et al., 1998). Other regulatory elements such as scaffolding proteins, phosphorylation, or dephosphorylation, etc. may also contribute to kinetic properties of synaptic currents.

In other central synapses, GluR2/3 subunits are critical for the constitutive recycling and trafficking of AMPARs in the postsynaptic density, whereas GluR1/4 subunits are driven into synapses by activity-dependent signaling cascades activated by $\mathrm{Ca}^{2+}$ influx through NMDARs (Sheng, 2001; Malinow and Malenka, 2002). In the context of previous studies that demonstrated a transient appearance of NMDARs over the same developmental time frame (Futai et al., 2001; Joshi and Wang, 2002), our study also raises an important question. Given that AMPARs are $\mathrm{Ca}^{2+}$ permeable from the very early stage of development, why are NMDARs needed at all? We postulate that NMDARs may be required for synapse formation and also provide more robust $\mathrm{Ca}^{2+}$ influx to support $\mathrm{Ca}^{2+}$-dependent recruitment and reorganization of AMPARs into the synaptic domain. However, activation of slow-gating NMDARs (independent of AMPARs) results in a prominent plateau potential and spontaneous off-phase firing in immature synapses (Futai et al., 2001). Thus, at the maturation stage when these processes are complete, NMDARs have to be downregulated to prevent $\mathrm{Ca}^{2+}$ overloading as well as to subsidize the plateau potential. Shortening of AMPAR EPSCs may present another refining adaptation for minimizing the plateau potential and maximizing the dynamic range of high-fidelity neurotransmission.

\section{High-frequency synaptic transmission requires fast decay kinetics}

The fidelity of the calyx of Held synapse in response to highfrequency inputs requires an effective integration of ligand-gated synaptic conductances and various voltage-gated conductances. By slowing the decay kinetics in older synapses with CTZ to mimic the decay phase of an immature synapse (Fig. $6 A-C$ ), we were able to specifically investigate the role of accelerating AMPAR decay kinetics in high-frequency neurotransmission, independent of many potential variables. One major concern with this set of experiments is that CTZ blocks desensitization of AMPARs and facilitates recovery from desensitization, which indirectly affects cell excitability and firing capability. Although there is evidence that AMPARs do desensitize in immature calyx of Held synapses (Neher and Sakaba, 2001; Wong et al., 2003), several studies have demonstrated that desensitization contributes very little, if any, to the extent and pattern of synaptic de- pression during trains of activity in mature synapses $(>\mathrm{P} 13)$, because neither parameter is significantly altered by CTZ (Wang and Kaczmarek, 1998; Joshi and Wang, 2002; Taschenberger et al., 2002). Perhaps this could be explained by the fact that the calyx of Held synapse has so many active zones (i.e., >600) with low release probabilities that the same postsynaptic sites are not repeatedly activated. Morphological transformation of an immature spoon-shape calyx to mature finger-digit-like calyx may help minimize glutamate accumulation in the synaptic cleft. In the context of these studies, we believe that our approach to manipulate decay kinetics of AMPAR EPSCs with CTZ provides insights into the physiological role of fast-gating AMPARs in the synaptic fidelity. Independent of any pharmacological manipulation, we have used another approach in which simulated EPSCs with defined amplitude and decay kinetics were used to drive spikes in mature MNTB neurons (Fig. 6E-G). In both cases, we found that spike responses to high-frequency stimuli were severely compromised when kinetics of EPSCs were prolonged, leading to an accumulative plateau potential. We suggest that such a plateau potential may result in partial inactivation of various voltage-gated conductances. Because a short-depolarizing current injection in control cells reduced spike size and broadened spike width (Fig. 6D), it is likely that $\mathrm{Na}^{+}$and $\mathrm{K}^{+}$currents were both affected by the plateau potential. It has been shown that a high-threshold potassium conductance $\left(I_{\mathrm{HT}}\right)$ is indispensable for MNTB neurons to fire at high rates (Brew and Forsythe, 1995; Wang et al., 1998). Injection of a hyperpolarizing current may remove inactivation of $\mathrm{Na}^{+}$current and $\mathrm{K}^{+}$conductances like $I_{\mathrm{HT}}$ and therefore rescue deficits in spike amplitude, particularly during high-frequency firing as we have demonstrated. Hence, we conclude that speeding of AMPAR kinetics plays an important role in enabling the calyx of Held-MNTB synapse to transmit at high frequencies with fidelity.

\section{References}

Bahring R, Mayer ML (1998) An analysis of philanthotoxin block for recombinant rat GluR6(Q) glutamate receptor channels. J Physiol (Lond) 509:635-650

Bellingham MC, Lim R, Walmsley B (1998) Developmental changes in EPSC quantal size and quantal content at a central glutamatergic synapse in rat. J Physiol (Lond) 511:861-869.

Bergles DE, Diamond JS, Jahr CE (1999) Clearance of glutamate inside the synapse and beyond. Curr Opin Neurobiol 9:293-298.

Borst JG, Sakmann B (1996) Calcium influx and transmitter release in a fast CNS synapse. Nature 383:431-434.

Bowie D, Mayer ML (1995) Inward rectification of both AMPA and kainate subtype glutamate receptors generated by polyamine-mediated ion channel block. Neuron 15:453-462.

Bowie D, Lange GD, Mayer ML (1998) Activity-dependent modulation of glutamate receptors by polyamines. J Neurosci 18:8175-8185.

Brew HM, Forsythe ID (1995) Two voltage-dependent $\mathrm{K}^{+}$conductances with complementary functions in postsynaptic integration at a central auditory synapse. J Neurosci 15:8011-8022.

Caicedo A, Eybalin M (1999) Glutamate receptor phenotypes in the auditory brainstem and mid-brain of the developing rat. Eur J Neurosci 11:51-74.

Carmignoto G, Vicini S (1992) Activity-dependent decrease in NMDA receptor responses during development of the visual cortex. Science 258:1007-1011.

Chuhma N, Ohmori H (1998) Postnatal development of phase-locked high-fidelity synaptic transmission in the medial nucleus of the trapezoid body of the rat. J Neurosci 18:512-520.

Colquhoun D, Jonas P, Sakmann B (1992) Action of brief pulses of gluta- 
mate on AMPA/kainate receptors in patches from different neurones of rat hippocampal slices. J Physiol (Lond) 458:261-287.

Constantine-Paton M, Cline HT (1998) LTP and activity-dependent synaptogenesis: the more alike they are, the more different they become. Curr Opin Neurobiol 8:139-148.

Denis MJ, Miledi R (1974) Characteristics of transmitter release at regenerating frog neuromuscular junctions. J Physiol (Lond) 239:571-594.

Dingledine R, Borges K, Bowie D, Traynelis SF (1999) The glutamate receptor ion channels. Pharmacol Rev 51:7-61.

Dodge Jr FA, Mildedi R, Rahamimoff R (1969) Strontium and quantal release of transmitter at the neuromuscular junction. J Physiol (Lond) 200:267-283.

Donevan SD, Rogawski MA (1995) Intracellular polyamines mediate inward rectification of $\mathrm{Ca}(2+)$-permeable alpha-amino-3-hydroxy-5methyl-4-isoxazolepropionic acid receptors. Proc Natl Acad Sci USA 92: 9298-9302.

Forsythe ID, Barnes-Davies M (1993) The binaural auditory pathway: membrane currents limiting multiple action potential generation in the rat medial nucleus of the trapezoid body. Proc R Soc Lond B Biol Sci 251:143-150.

Futai K, Okada M, Matsuyama K, Takahashi T (2001) High-fidelity transmission acquired via a developmental decrease in NMDA receptor expression at an auditory synapse. J Neurosci 21:3342-3349.

Gardner SM, Trussell LO, Oertel D (1999) Time course and permeation of synaptic AMPA receptors in cochlear nuclear neurons correlate with input. J Neurosci 19:8721-8729.

Geiger JR, Melcher T, Koh DS, Sakmann B, Seeburg PH, Jonas P, Monyer H (1995) Relative abundance of subunit mRNAs determines gating and $\mathrm{Ca}^{2+}$ permeability of AMPA receptors in principal neurons and interneurons in rat CNS. Neuron 15:193-204.

Goda Y, Stevens CF (1994) Two components of transmitter release at a central synapse. Proc Natl Acad Sci USA 91:12942-12946.

Gottmann K, Mehrle A, Gisselmann G, Hatt H (1997) Presynaptic control of subunit composition of NMDA receptors mediating synaptic plasticity. J Neurosci 17:2766-2774.

Hestrin S (1992) Developmental regulation of NMDA receptor-mediated synaptic currents at a central synapse. Nature 357:686-689.

Hua SY, Raciborska DA, Trimble WS, Charlton MP (1998) Different VAMP/ synaptobrevin complexes for spontaneous and evoked transmitter release at the crayfish neuromuscular junction. J Neurophysiol 80:3233-3246.

Hunter C, Petralia RS, Vu T, Wenthold RJ (1993) Expression of AMPAselective glutamate receptor subunits in morphologically defined neurons of the mammalian cochlear nucleus. J Neurosci 13:1932-1946.

Ishikawa T, Takahashi T (2001) Mechanisms underlying presynaptic facilitatory effect of cyclothiazide at the calyx of Held of juvenile rats. J Physiol (Lond) 533:423-431.

Iwasaki S, Takahashi T (2001) Developmental regulation of transmitter release at the calyx of Held in rat auditory brainstem. J Physiol (Lond) 534:861-871.

Jonas P, Racca C, Sakmann B, Seeburg PH, Monyer H (1994) Differences in $\mathrm{Ca}^{2+}$ permeability of AMPA-type glutamate receptor channels in neocortical neurons caused by differential GluR-B subunit expression. Neuron 12:1281-1289.

Jones MV, Westbrook GL (1996) The impact of receptor desensitization on fast synaptic transmission. Trends Neurosci 19:96-101.

Jones MV, Sahara Y, Dzubay JA, Westbrook GL (1998) Defining affinity with the $\mathrm{GABA}_{\mathrm{A}}$ receptor. J Neurosci 18:8590-8604.

Joshi I, Wang LY (2002) Developmental profiles of glutamate receptors and synaptic transmission at a single synapse in the mouse auditory brainstem. J Physiol (Lond) 540:861-873.

Joshi I, Shokralla S, Chazot PY, Thompson CL, Wang LY (2001) Glutamate receptor subunit composition at single developing central synapses. Soc Neurosci Abstr 27:502.12.

Kamboj SK, Swanson GT, Cull-Candy SG (1995) Intracellular spermine confers rectification on rat calcium-permeable AMPA and kainate receptors. J Physiol (Lond) 486:297-303.

Koh DS, Geiger JR, Jonas P, Sakmann B (1995) Ca(2+)-permeable AMPA and NMDA receptor channels in basket cells of rat hippocampal dentate gyrus. J Physiol (Lond) 485:383-402.

Kumar SS, Bacci A, Kharazia V, Huguenard JR (2002) A developmental switch of AMPA receptor subunits in neocortical pyramidal neurons. J Neurosci 22:3005-3015.
Lawrence JJ, Trussell LO (2000) Long-term specification of AMPA receptor properties after synapse formation. J Neurosci 20:4864-4870.

Liu SQ, Cull-Candy SG (2000) Synaptic activity at calcium-permeable AMPA receptors induces a switch in receptor subtype. Nature 405:454-458.

Mainen ZF, Jia Z, Roder J, Malinow R (1998) Use-dependent AMPA receptor block in mice lacking GluR2 suggests postsynaptic site for LTP expression. Nat Neurosci 1:579-586.

Malinow R, Malenka RC (2002) AMPA receptor trafficking and synaptic plasticity. Annu Rev Neurosci 25:103-126.

Monyer H, Burnashev N, Laurie DJ, Sakmann B, Seeburg PH (1994) Developmental and regional expression in the rat brain and functional properties of four NMDA receptors. Neuron 12:529-540.

Neher E, Sakaba T (2001) Combining deconvolution and noise analysis for the estimation of transmitter release rates at the calyx of Held. J Neurosci 21:444-461.

Otis TS, Raman IM, Trussell LO (1995) AMPA receptors with high $\mathrm{Ca}^{2+}$ permeability mediate synaptic transmission in the avian auditory pathway. J Physiol (Lond) 482:309-315.

Panchenko VA, Glasser CR, Partin KM, Mayer ML (1999) Amino acid substitutions in the pore of rat glutamate receptors at sites influencing block by polyamines. J Physiol (Lond) 520:337-357.

Patneau DK, Vyklicky Jr L, Mayer ML (1993) Hippocampal neurons exhibit cyclothiazide-sensitive rapidly desensitizing responses to kainate. J Neurosci 13:3496-3509.

Petralia RS, Wang YX, Zhao HM, Wenthold RJ (1996) Ionotropic and metabotropic glutamate receptors show unique postsynaptic, presynaptic, and glial localizations in the dorsal cochlear nucleus. J Comp Neurol 372:356-383

Raman IM, Trussell LO (1995) Concentration-jump analysis of voltagedependent conductances activated by glutamate and kainate in neurons of the avian cochlear nucleus. Biophys J 69:1868-1879.

Raman IM, Zhang S, Trussell LO (1994) Pathway-specific variants of AMPA receptors and their contribution to neuronal signaling. J Neurosci 14:4998-5010.

Ravindranathan A, Donevan SD, Sugden SG, Greig A, Rao MS, Parks TN (2000) Contrasting molecular composition and channel properties of AMPA receptors on chick auditory and brainstem motor neurons. J Physiol (Lond) 523:667-684.

Rubio ME, Wenthold RJ (1997) Glutamate receptors are selectively targeted to postsynaptic sites in neurons. Neuron 18:939-950.

Sheng M (2001) Molecular organization of the postsynaptic specialization. Proc Natl Acad Sci USA 98:7058-7061.

Singer JH, Talley EM, Bayliss DA, Berger AJ (1998) Development of glycinergic synaptic transmission to rat brain stem motoneurons. J Neurophysiol 80:2608-2620.

Takahashi T, Momiyama A, Hirai K, Hishinuma F, Akagi H (1992) Functional correlation of fetal and adult forms of glycine receptors with developmental changes in inhibitory synaptic receptor channels. Neuron 9:1155-1161.

Takahashi T, Feldmeyer D, Suzuki N, Onodera K, Cull-Candy SG, Sakimura K, Mishina M (1996) Functional correlation of NMDA receptor $\epsilon$ subunits expression with the properties of single-channel and synaptic currents in the developing cerebellum. J Neurosci 16:4376-4382.

Taschenberger H, von Gersdorff H (2000) Fine-tuning an auditory synapse for speed and fidelity: developmental changes in presynaptic waveform, EPSC kinetics, and synaptic plasticity. J Neurosci 20:9162-9173.

Taschenberger H, Leao RM, Rowland KC, Spirou GA, von Gersdorff H (2002) Optimizing synaptic architecture and efficiency for highfrequency transmission. Neuron 36:1127-1143.

Tia S, Wang JF, Kotchabhakdi N, Vicini S (1996) Developmental changes of inhibitory synaptic currents in cerebellar granule neurons: role of GABA(A) receptor $\alpha 6$ subunit. J Neurosci 16:3630-3640.

Trussell LO (1999) Synaptic mechanisms for coding timing in auditory neurons. Annu Rev Physiol 61:477-496.

von Gersdorff H, Borst JG (2002) Short-term plasticity at the calyx of Held. Nat Rev Neurosci 3:53-64.

von Gersdorff H, Schneggenburger R, Weis S, Neher E (1997) Presynaptic depression at a calyx synapse: the small contribution of metabotropic glutamate receptors. J Neurosci 17:8137-8146. 
Wall MJ, Robert A, Howe JR, Usowicz MM (2002) The speeding of EPSC kinetics during maturation of a central synapse. Eur J Neurosci 15:785-797.

Wang LY (2000) The dynamic range for gain control of NMDA receptor-mediated synaptic transmission at a single synapse. J Neurosci 20:RC115(1-5).

Wang LY, Kaczmarek LK (1998) High-frequency firing helps replenish the readily releasable pool of synaptic vesicles. Nature 394:384-388.

Wang YX, Wenthold RJ, Ottersen OP, Petralia RS (1998) Endbulb synapses in the anteroventral cochlear nucleus express a specific subset of AMPAtype glutamate receptor subunits. J Neurosci 18:1148-1160.

Washbourne P, Bennett JE, McAllister AK (2002) Rapid recruitment of NMDA receptor transport packets to nascent synapses. Nat Neurosci 5:751-759.

Washburn MS, Dingledine R (1996) Block of alpha-amino-3-hydroxy-5-- methyl-4-isoxazolepropionic acid (AMPA) receptors by polyamines and polyamine toxins. J Pharmacol Exp Ther 278:669-678.

Washburn MS, Numberger M, Zhang S, Dingledine R (1997) Differential dependence on GluR2 expression of three characteristic features of AMPA receptors. J Neurosci 17:9393-9406.

Wong AY, Graham BP, Billups B, Forsythe ID (2003) Distinguishing between presynaptic and postsynaptic mechanisms of short-term depression during action potential trains. J Neurosci 23:4868-4877.

Xu-Friedman MA, Regehr WG (1999) Presynaptic strontium dynamics and synaptic transmission. Biophys J 76:2029-2042.

Zhou N, Taylor DA, Parks TN (1995) Cobalt-permeable non-NMDA receptors in developing chick brainstem auditory nuclei. NeuroReport 6:2273-2276. 